Prepared in cooperation with the WaterSMART Initiative

\title{
Estimating Irrigation Water Use in the Humid Eastern United States
}

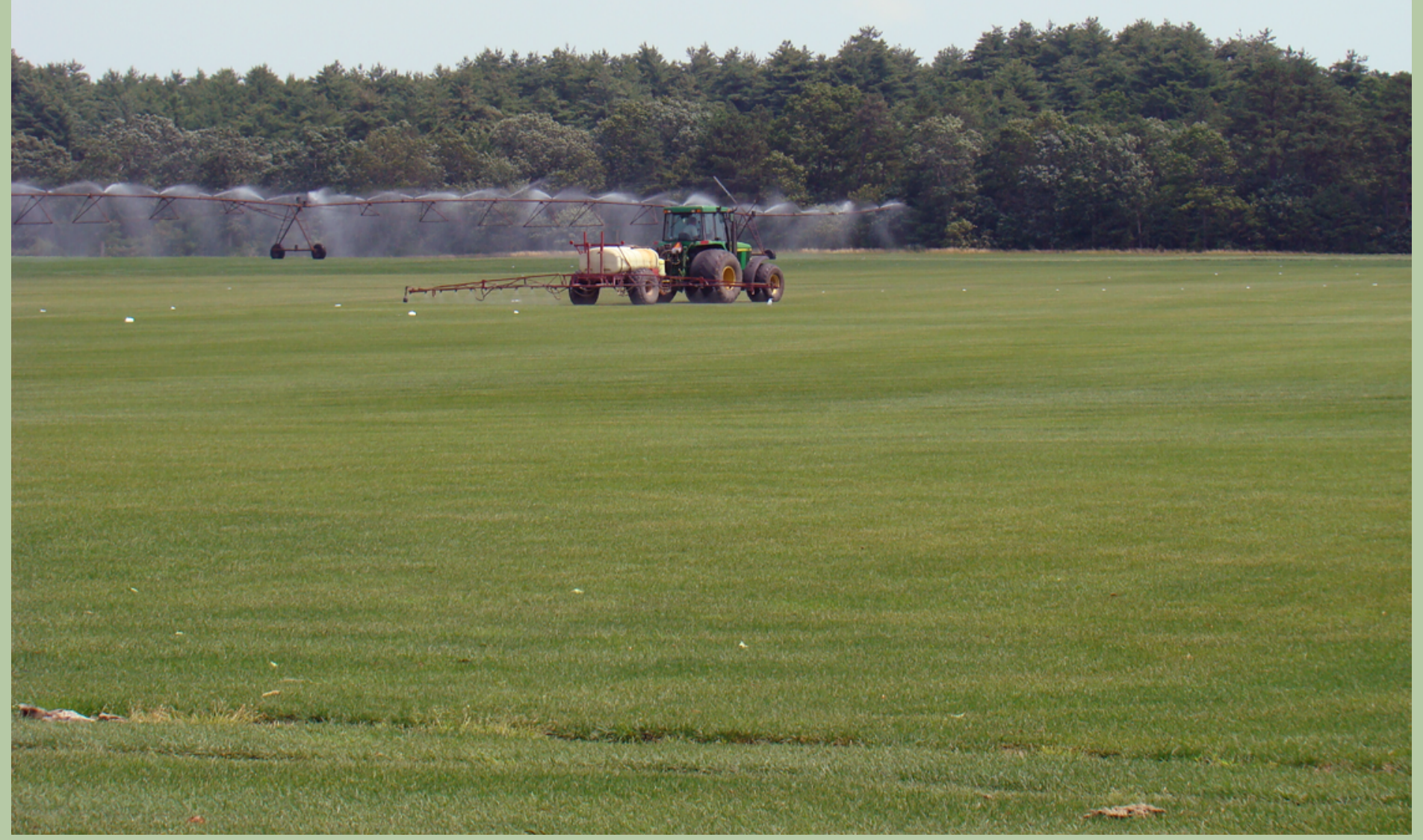

Scientific Investigations Report 2013-5066 
Cover photographs. Turf farm in southern New England. Photographs by Gardner Bent, U.S. Geological Survey. 


\section{Estimating Irrigation Water Use in the Humid Eastern United States}

By Sara B. Levin and Phillip J. Zarriello

Prepared in cooperation with the WaterSMART Initiative

Scientific Investigations Report 2013-5066 


\title{
U.S. Department of the Interior SALLY JEWELL, Secretary
}

\section{U.S. Geological Survey Suzette M. Kimball, Acting Director}

\author{
U.S. Geological Survey, Reston, Virginia: 2013
}

For more information on the USGS - the Federal source for science about the Earth, its natural and living resources, natural hazards, and the environment, visit http://www.usgs.gov or call 1-888-ASK-USGS.

For an overview of USGS information products, including maps, imagery, and publications, visit http://www.usgs.gov/pubprod

To order this and other USGS information products, visit http://store.usgs.gov

Any use of trade, firm, or product names is for descriptive purposes only and does not imply endorsement by the U.S. Government.

Although this information product, for the most part, is in the public domain, it also may contain copyrighted materials as noted in the text. Permission to reproduce copyrighted items must be secured from the copyright owner.

Suggested citation:

Levin, S.B., and Zarriello, P.J., 2013, Estimating irrigation water use in the humid eastern United States: U.S. Geological Survey Scientific Investigations Report 2013-5066, 32 p., http://pubs.usgs.gov/sir/2013/5066/. 


\section{Acknowledgments}

The authors thank the Georgia Soil and Water Conservation Commission and the Virginia Department of Environmental Quality for allowing access to their irrigation water-use data. The authors also thank Lynn Torak of the U.S. Geological Survey for his assistance in accessing the Georgia irrigation data and in data compilation and interpretation. 
THIS PAGE INTENTIONALLY LEFT BLANK 


\section{Contents}

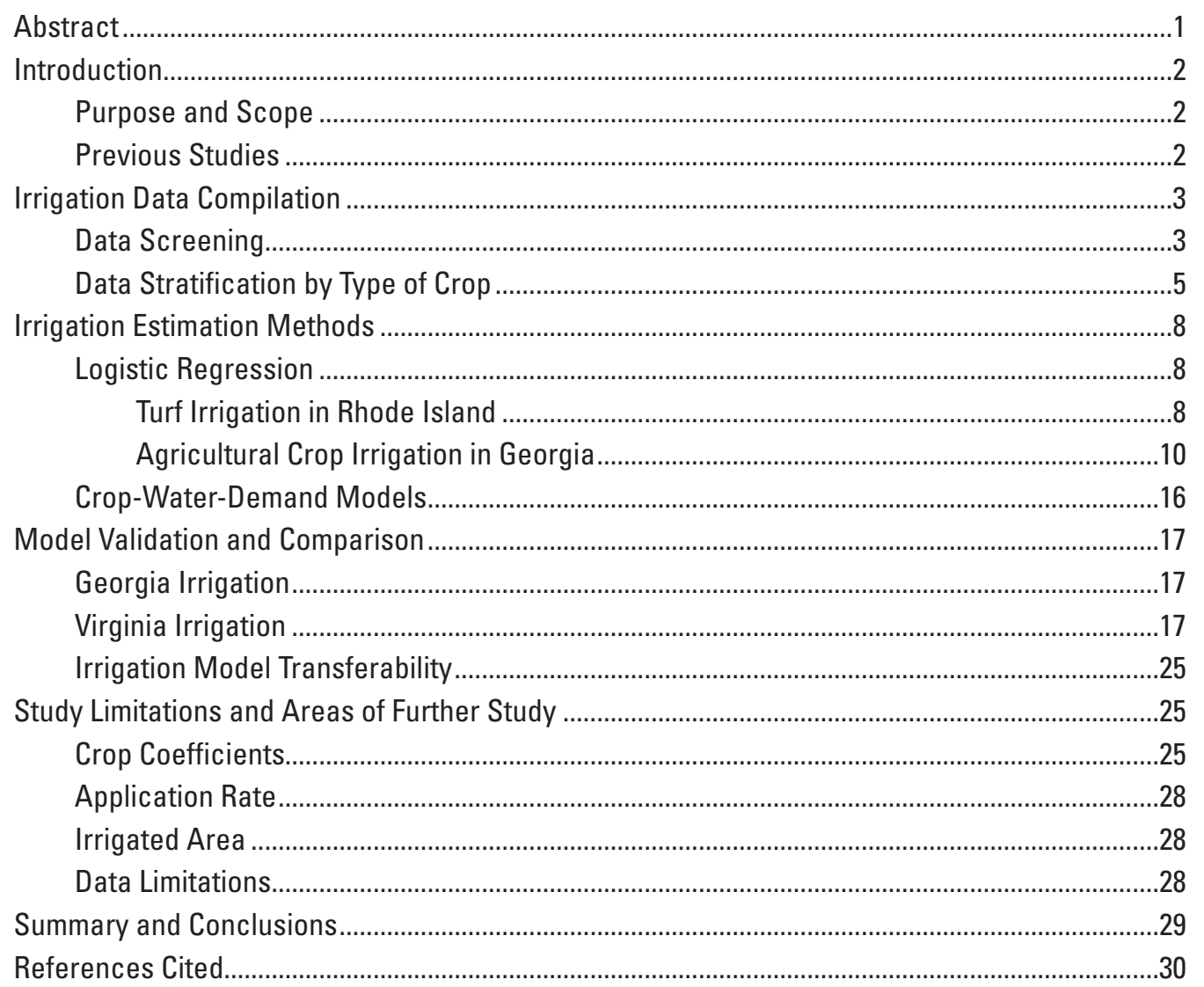




\section{Figures}

1. Map showing locations of irrigation sites with daily and weekly irrigation data from 2009 and 2010 and National Climatic Data Center climate stations in southern Georgia

2. Map showing example overlay of meter locations with Cropland Data Layer and Georgia irrigated lands geospatial dataset..

3. Graphs showing monthly irrigation water use during 2009 and 2010 at $A, 6$ corn; $B, 18$ cotton; $C, 6$ peanut; and $D, 6$ soybean fields in southern Georgia

4. Graph showing reported data and model estimates of annual irrigation from 2000 to 2004 at nine turf farms in Rhode Island.

5. Graphs showing crop coefficients for $A$, corn; $B$, cotton; $C$, peanuts; and $D$, soybeans for Georgia and $E$, turf for Rhode Island

6. Graph showing reported data and model estimates of 2009 and 2010 seasonal irrigation (May through October) for corn, cotton, peanut, and soybean crops in Georgia

7. Map showing metered irrigation sites with 2010 annual data and National Climatic Data Center climate stations in southwestern Georgia

8. Graphs showing reported data and model estimates of 2010 annual irrigation for $A$, corn; $B$, cotton; $C$, peanut; and $D$, soybean fields for selected counties in southwestern Georgia

9. Graphs showing reported data and model estimates of annual irrigation by county, for $A$, corn; $B$, cotton; $C$, soybeans; and $D$, turf crops in Virginia from 1999 to 2007........23

10. Graphs showing reported data and model estimates of mean monthly irrigation from 1999 to 2007 for $A$, corn; $B$, cotton; $C$, soybean; and $D$, turf farms in Virginia

\section{Tables}

1. Irrigation data compiled from New England and mid-Atlantic states .

2. Reported data and model estimates of annual irrigation for turf farms during 2000 to 2004 in Rhode Island, and corn, cotton, peanut, and soybean farms during 2009 and 2010 in southern Georgia

3. Summary statistics for logistic regression equations developed for predicting weekly irrigation during the 2009 and 2010 growing season for corn, cotton, peanut, and soybean crops in Georgia.

4. Seasonal median irrigation (May to October) during 2009 and 2010 for 6 corn, 18 cotton, 6 peanut, and 6 soybean sites in Georgia

5. Reported data and model estimates of seasonal 2010 annual irrigation for corn, cotton, peanut, and soybean fields for selected counties in southwestern Georgia .....20

6. Reported and simulated mean annual irrigation from 1999 to 2007 for corn, cotton, soybean, and turf farms in Virginia...

7. Primary irrigated crops in eastern states, by acreage, reported in the 2008 Farm and Ranch Irrigation Survey 


\section{Conversion Factors, Datum, and Abbreviations}

Inch/Pound to SI

\begin{tabular}{lcl}
\hline \multicolumn{1}{c}{ Multiply } & By & \multicolumn{1}{c}{ To obtain } \\
\hline inch (in.) & Length & \\
inch (in.) & 2.54 & centimeter $(\mathrm{cm})$ \\
\hline \multicolumn{3}{c}{ millimeter $(\mathrm{mm})$} \\
\hline acre & 25.4 & \\
\hline & Area & square meter $\left(\mathrm{m}^{2}\right)$ \\
\hline gallon (gal) & Volume & \\
million gallons (Mgal) & 231 & cubic inches $\left(\mathrm{in}^{3}\right)$ \\
\hline & 3,785 & cubic meter $\left(\mathrm{m}^{3}\right)$ \\
\hline acre-foot per year (acre-ft/yr) & Flow rate & \\
acre-foot per year (acre-ft/yr) & 1.233 & cubic meter per year $\left(\mathrm{m}^{3} / \mathrm{yr}\right)$ \\
gallon per day (gal/d) & 0.001233 & cubic hectometer per year $(\mathrm{hm} / \mathrm{yr})$ \\
inch per day (in/d) & 0.003785 & cubic meter per day $\left(\mathrm{m}^{3} / \mathrm{d}\right)$ \\
inch per year (in/yr) & 25.4 & millimeter per day $(\mathrm{mm} / \mathrm{d})$ \\
million gallons per day (Mgal/d) & 25.4 & millimeter per year $(\mathrm{mm} / \mathrm{yr})$ \\
\hline
\end{tabular}

Temperature in degrees Celsius $\left({ }^{\circ} \mathrm{C}\right)$ may be converted to degrees Fahrenheit $\left({ }^{\circ} \mathrm{F}\right)$ as follows:

$$
{ }^{\circ} \mathrm{F}=\left(1.8 \times^{\circ} \mathrm{C}\right)+32
$$

Temperature in degrees Fahrenheit $\left({ }^{\circ} \mathrm{F}\right)$ may be converted to degrees Celsius $\left({ }^{\circ} \mathrm{C}\right)$ as follows:

$$
{ }^{\circ} \mathrm{C}=\left({ }^{\circ} \mathrm{F}-32\right) / 1.8
$$

Vertical coordinate information is referenced to North American Vertical Datum of 1988 (NAVD 88).

Horizontal coordinate information is referenced to North American Datum of 1983 (NAD 83).

Altitude, as used in this report, refers to distance above the vertical datum. 


\section{Abbreviations}

$\begin{array}{ll}\text { AIC } & \text { Akaike Information Criteria } \\ \text { CDL } & \text { cropland data layer } \\ \text { CPET } & \text { crop-specific potential evapotranspiration } \\ \text { FAO } & \text { Food and Agriculture Organization of the United Nations } \\ \text { FRIS } & \text { Farm and Ranch Irrigation Survey } \\ \text { MAD } & \text { management allowed depletion } \\ \text { NCDC } & \text { National Climatic Data Center } \\ \text { NDVI } & \text { normalized difference vegetation index } \\ \text { NOAA } & \text { National Oceanic and Atmospheric Administration } \\ \text { NWUIP } & \text { National Water-Use Information Program } \\ \text { PET } & \text { potential evapotranspiration } \\ \text { RMSE } & \text { root mean squared error } \\ \text { Smax } & \text { maximum soil water } \\ \text { USDA } & \text { U.S. Department of Agriculture } \\ \text { USGS } & \text { U.S. Geological Survey }\end{array}$




\title{
Estimating Irrigation Water Use in the Humid Eastern United States
}

\author{
By Sara B. Levin and Phillip J. Zarriello
}

\section{Abstract}

Accurate accounting of irrigation water use is an important part of the U.S. Geological Survey National Water-Use Information Program and the WaterSMART initiative to help maintain sustainable water resources in the Nation. Irrigation water use in the humid eastern United States is not well characterized because of inadequate reporting and wide variability associated with climate, soils, crops, and farming practices. To better understand irrigation water use in the eastern United States, two types of predictive models were developed and compared by using metered irrigation water-use data for corn, cotton, peanut, and soybean crops in Georgia and turf farms in Rhode Island. Reliable metered irrigation data were limited to these areas.

The first predictive model that was developed uses logistic regression to predict the occurrence of irrigation on the basis of antecedent climate conditions. Logistic regression equations were developed for corn, cotton, peanut, and soybean crops by using weekly irrigation water-use data from 36 metered sites in Georgia in 2009 and 2010 and turf farms in Rhode Island from 2000 to 2004. For the weeks when irrigation was predicted to take place, the irrigation water-use volume was estimated by multiplying the average metered irrigation application rate by the irrigated acreage for a given crop.

The second predictive model that was developed is a crop-water-demand model that uses a daily soil water balance to estimate the water needs of a crop on a given day based on climate, soil, and plant properties. Crop-water-demand models were developed independently of reported irrigation water-use practices and relied on knowledge of plant properties that are available in the literature. Both modeling approaches require accurate accounting of irrigated area and crop type to estimate total irrigation water use.

Water-use estimates from both modeling methods were compared to the metered irrigation data from Rhode Island and Georgia that were used to develop the models as well as two independent validation datasets from Georgia and Virginia that were not used in model development. Irrigation water-use estimates from the logistic regression method more closely matched mean reported irrigation rates than estimates from the crop-water-demand model when compared to the irrigation data used to develop the equations. The root mean squared errors (RMSEs) for the logistic regression estimates of mean annual irrigation ranged from 0.3 to 2.0 inches (in.) for the five crop types; RMSEs for the crop-water-demand models ranged from 1.4 to $3.9 \mathrm{in}$. However, when the models were applied and compared to the independent validation datasets from southwest Georgia from 2010, and from Virginia from 1999 to 2007 , the crop-water-demand model estimates were as good as or better at predicting the mean irrigation volume than the logistic regression models for most crop types. RMSEs for logistic regression estimates of mean annual irrigation ranged from 1.0 to 7.0 in. for validation data from Georgia and from 1.8 to 4.9 in. for validation data from Virginia; RMSEs for crop-water-demand model estimates ranged from 2.1 to $5.8 \mathrm{in}$. for Georgia data and from 2.0 to $3.9 \mathrm{in}$. for Virginia data. In general, regression-based models performed better in areas that had quality daily or weekly irrigation data from which the regression equations were developed; however, the regression models were less reliable than the crop-waterdemand models when applied outside the area for which they were developed. In most eastern coastal states that do not have quality irrigation data, the crop-water-demand model can be used more reliably.

The development of predictive models of irrigation water use in this study was hindered by a lack of quality irrigation data. Many mid-Atlantic and New England states do not require irrigation water use to be reported. A survey of irrigation data from 14 eastern coastal states from Maine to Georgia indicated that, with the exception of the data in Georgia, irrigation data in the states that do require reporting commonly did not contain requisite ancillary information such as irrigated area or crop type, lacked precision, or were at an aggregated temporal scale making them unsuitable for use in the development of predictive models. Confidence in the reliability of either modeling method is affected by uncertainty in the reported data from which the models were developed or validated. Only through additional collection of quality data and further study can the accuracy and uncertainty of irrigation water-use estimates be improved in the humid eastern United States. 


\section{Introduction}

Human water use, climate change, and the recognition of shared water resources for ecological needs are increasing the strain on freshwater resources in many regions of the United States. To manage water resources, particularly those at risk, sound estimates of human water demands and ecological needs are required. Irrigation is the largest consumptive use of water in the Nation. That is, unlike many other water uses that are returned or recycled back into the environment and can be reused, over half the water used for irrigation nationally is lost through evapotranspiration (Solly and others, 1998). Every 5 years, the U.S. Geological Survey (USGS) National WaterUse Information Program (NWUIP) reports on water use across the country. The information is compiled from many sources at state and local levels and is aggregated to provide information on water uses, volumes, and sources by state. The 2005 NWUIP compilation reported that irrigation water use totaled 128,000 million gallons per day (Mgal/d) and composed 37 percent of the total freshwater withdrawals in the country, second only to withdrawals for thermoelectric power (Kenny and others, 2009).

Irrigation water use is relatively small in the humid New England and mid-Atlantic States relative to the arid and semiarid western states, where most of the crop water demand is met by irrigation. In the humid east, farmers commonly rely heavily on frequent summer rainfall to meet crop water needs. According to the 2008 Farm and Ranch Irrigation Survey (FRIS) report, irrigated farms represented only 20 and 30 percent of the total crop farms in New England and the mid-Atlantic regions, respectively (U.S. Department of Agriculture, National Agricultural Statistics Service, 2009a). However, there is evidence that irrigation is becoming more common in these regions. The acreage of irrigated land in New England increased by 3 percent from 2003 to 2008 despite a 35 percent decrease in the total acreage of farmland. In the mid-Atlantic region, irrigated acreage increased by 33 percent during this time; whereas the total acreage of farmland increased by only 6 percent (U.S. Department of Agriculture, National Agricultural Statistics Service, 2009a).

The large consumptive use of water for irrigation underscores the importance of accurate monitoring and accounting of irrigation water use at the local, state, and national levels. However, estimating irrigation water use is difficult, especially in the eastern United States, because of its high variability and the lack of reporting standards. Irrigation water use varies widely due to climate conditions, crop and soil type, and differences in irrigation practices. This variability and the uncertainty in reported irrigation data result in inconsistent estimates of irrigation water use from different sources. The U.S. Department of Agriculture (USDA) Census of Agriculture and conjunctive FRIS provide major sources of supplemental information that support the development of NWUIP irrigation estimates, but this information is compiled on a 5-year cycle that is offset from the 5 -year NWUIP compilation by 3 years. The 2008 FRIS reported irrigation water use of 91.3 million acre-feet per year (about $83,400 \mathrm{Mgal} / \mathrm{d}$ ) of water in the United States. This is about 50 percent less than the irrigation water use reported in the 2005 NWUIP. Although irrigation can vary appreciably by year and region, differences of this magnitude may also be attributed to the quality of the irrigation water-use information used by the USGS and USDA and the methods used to analyze that information.

To better account for irrigation water use in the humid eastern part of the Nation, the USGS WaterSMART initiative is examining existing irrigation water-use data and is developing methods to better estimate irrigation water use. This study is part of the WaterSMART initiative to provide information and tools to those working in water-resource planning and for the management of sustainable water resources for the Nation.

\section{Purpose and Scope}

The purpose of this report was to present and compare models for estimating irrigation water use in humid New England and mid-Atlantic States and to assess the feasibility and data needs for implementing these estimation methods on a regional scale within the study area. Two methods of estimating crop irrigation water use were developed from existing metered data in Georgia and Rhode Island. The first method uses logistic regression equations to predict the occurrence of irrigation on a given week on the basis of antecedent climate variables and estimates of irrigation volume by using average water application rates. Logistic regression equations were developed for corn, cotton, peanut, and soybean crops in Georgia and turf farms in Rhode Island. The second method uses a daily water balance to predict irrigation on a given day based on climate, soil, and plant properties. The models were developed for the same five crops. Water-use estimates from both models were compared to independent datasets from Georgia and Virginia that were not used in model development.

\section{Previous Studies}

Zarriello and Bent (2004) developed logistic regression equations to predict the occurrence of daily irrigation for turf farms and golf courses in Rhode Island from antecedent precipitation and potential evapotranspiration (PET). These equations were revised with updated data by Bent and others (2009) and applied to a broader area of Rhode Island. The logistic regression equations accurately predicted daily irrigation 78 percent of the time for turf farms and 79 percent of the time for golf courses. On days when irrigation was predicted, water-use volumes were estimated by multiplying the average withdrawal rate per acre by the number of acres irrigated.

Fanning and others (2001) predicted irrigation water use in Georgia from five regression equations developed from withdrawal-permit information. The five equations predict (1) whether or not irrigation will be used at a given location, (2) the crop type, (3) the irrigated acreage, (4) the planting and 
harvesting dates, and (5) the volume of water applied. Model estimates of countywide irrigation in Georgia during the 1996 growing season (March through October) were roughly 15 percent higher than irrigation determined from a sample of metered irrigation data.

Although more commonly used in arid, water-scarce environments, physically based simulation models of crop water demand have been used in the eastern United States to estimate irrigation water requirements in Florida (Satti and others, 2004) and Georgia (Guerra and others, 2007), as well as potential changes in irrigation needs in the southeast United States under several climate-change scenarios (Peart and others, 1995). Additionally, the crop-water-demand method is incorporated into a more general soil water balance model that uses gridded climate and soil data to calculate spatially explicit groundwater-recharge estimates of soil water (Westenbroek and others, 2010).

\section{Irrigation Data Compilation}

Irrigation water-use data for this study were initially compiled for the coastal eastern United States from 13 states from North Carolina to Maine (table 1). The available irrigation data for these states were usually limited to the spatially and temporally aggregated information reported in the 5-year compilations for the NWUIP and the FRIS, which are not well suited to developing tools for estimating irrigation water use. About half the states in the study area have no reporting requirement. States that do have reporting requirements vary widely in the types of information that are required (irrigation volume, irrigated acreage, crop type, irrigation method, and water source), the reporting time scale (daily, monthly, or annual usage), and whether the data were metered, estimated from average pumping times, or determined by other means. These data are typically aggregated over a growing season and often lack quality assurance, which limited the use of this data. The study area was later expanded to include Georgia because of the availability of quality metered irrigation data (table 1).

The availability of irrigation water-use data varied by state. Site-specific irrigation water-use data were either not reported or were unavailable because of confidentiality agreements in Delaware, Maine, Massachusetts, New Hampshire, New York, and Vermont. In Rhode Island, metered irrigation data were collected by the USGS at nine turf farms and four golf courses from 2000 to 2004 for a detailed basin study. These data were used to develop predictive equations for irrigation use on turf farms and golf courses (Bent and others, 2009, Zarriello and Bent, 2004). Connecticut, Maryland, Pennsylvania and New Jersey required reporting of monthly irrigation volumes for agricultural crops and golf courses. These data were estimated from pumping rates or other non-metered methods, and ancillary information, such as irrigated acreage and crop type, were not reported. In Virginia, monthly irrigation volumes were available from 1999 to 2009 at about 800 agricultural sites. Irrigated acreage and crop information were reported for roughly half of these sites. In North Carolina, estimated daily irrigation volumes for golf courses, nurseries, and farms were available from 1983 to 2010; however, irrigated acreage was not available, and croptype information was limited. In Georgia since 2004, metered irrigation is required and is reported for all agricultural water use (Georgia General Assembly, 2003). Metered irrigation data from Georgia that were available for this study included daily volumes at 54 sites for the 2009 growing season and weekly irrigation volumes at 75 sites for the 2010 growing season. In addition, metered annual irrigation volumes were available for over 4,000 sites in southwestern Georgia during 2010. Irrigated acreage was reported at about half of the sites.

\section{Data Screening}

Irrigation data obtained from states within the study area were screened for use in developing predictive irrigation water-use models. Irrigation data from Connecticut, Maryland, and New Jersey were not suited for use in this study because the data did not include information regarding irrigated acreage and crop type, which are needed for model development. Irrigated acreage associated with a reported volume is required to normalize the water-use data to a volume-per-unit-area measurement to account for the large range in irrigation volumes associated with varying field sizes. Information concerning crop type is important because irrigation needs over the growing cycle vary for different crops. For example, in Georgia, corn is usually planted in March and harvested by July. Corn is most susceptible to water stress during the tasseling and silking phase of growth, which is roughly 60 to 70 days after planting, around May and June (Lee, 2012). Susceptibility to water stress declines after this period, and corn crops can require little or no irrigation during the hottest summer months when the corn is nearing harvest. Cotton is usually planted in May in Georgia, and in contrast to corn, cotton is fairly drought tolerant after germination through early growth. Consequently, cotton farmers with limited water sources may withhold irrigation after early growth so that water is available during the more critical fruiting phase in late July and August when the crop is more susceptible to drought. The large differences in crop-specific water use make this piece of information crucial for model development.

Reported irrigation water-use data were screened to identify potential problems with data quality or accuracy. Of the states in the study that require reporting of irrigation water use, only Georgia requires metering. Data from other states are unmetered and, at best, the water use is estimated by the pumping capacity of the irrigation system multiplied by the hours of operation, which is usually not well tracked. The uncertainty in these water-use estimates creates noise in the data that precludes the development of statistical models of acceptable significance or the validation of physical crop models with the reported irrigation water use. 
Table 1. Irrigation data compiled from New England and mid-Atlantic states.

[--, no information]

\begin{tabular}{|c|c|c|c|c|}
\hline State & $\begin{array}{l}\text { Period of } \\
\text { record }\end{array}$ & Available data & $\begin{array}{c}\text { Water-use } \\
\text { estimation method }\end{array}$ & Notes \\
\hline Connecticut & $1997-2001$ & $\begin{array}{l}\text { Monthly irrigation volumes for golf courses, nurseries, } \\
\text { and farms. }\end{array}$ & $\begin{array}{l}\text { Average pumping } \\
\text { rates }\end{array}$ & $\begin{array}{l}\text { Data not georeferenced. } \\
\text { Acreage and crop type not } \\
\text { available. }\end{array}$ \\
\hline Delaware & & Data not collected or unavailable. & -- & -- \\
\hline Georgia & $2009-2010$ & $\begin{array}{l}\text { Daily irrigation volumes for } 2009 \text { and weekly volumes } \\
\text { for 2010. Annual volumes at a larger set of farms for } \\
\text { 2010. Irrigated acreage available at some sites. }\end{array}$ & Metered data & Limited crop-type information. \\
\hline Maine & & Data not collected or unavailable. & -- & -- \\
\hline Maryland & $1980-2005$ & Monthly irrigation volumes and water source type. & Unknown & $\begin{array}{l}\text { Acreage and crop type not } \\
\text { available. }\end{array}$ \\
\hline Massachusetts & & Data not collected or unavailable. & -- & -- \\
\hline New Hampshire & & Data not collected or unavailable. & -- & -- \\
\hline New Jersey & $2003-2008$ & Monthly and annual irrigation volumes. & Unknown & $\begin{array}{l}\text { Acreage and crop type not } \\
\text { available. }\end{array}$ \\
\hline New York & & Data unavailable due to confidentiality agreements. & -- & -- \\
\hline North Carolina & $1983-2010$ & $\begin{array}{l}\text { Daily irrigation volumes for golf courses, nurseries, } \\
\text { and farms. }\end{array}$ & Estimated & $\begin{array}{l}\text { Acreage not available. Limited } \\
\text { crop type information. }\end{array}$ \\
\hline Pennsylvania & 2003 & $\begin{array}{l}\text { Monthly irrigation volumes and water source type } \\
\text { (groundwater or surface water). }\end{array}$ & Mostly estimated & $\begin{array}{l}\text { Acreage and crop type not } \\
\text { available. }\end{array}$ \\
\hline Rhode Island & $2000-2007$ & $\begin{array}{l}\text { Daily irrigation volumes and irrigated acreage for } \\
\text { selected turf farms and golf courses. }\end{array}$ & Metered daily data & -- \\
\hline Vermont & & Data not collected or unavailable. & -- & -- \\
\hline Virginia & 1999-2009 & $\begin{array}{l}\text { Monthly irrigation volumes and water source type for } \\
\text { golf courses, nurseries, and farms. }\end{array}$ & $\begin{array}{l}\text { Mostly estimated, } \\
\text { several metered }\end{array}$ & Limited crop-type and acreage. \\
\hline
\end{tabular}


Initial screening of the reported irrigation data revealed inconsistencies and quality issues associated with some reported water-use volumes. For example, two farms in North Carolina report daily irrigation during large tropical storms or hurricanes when they received about 7 to 10 inches (in.) of precipitation over a 2-day period. Even though farms could have automated irrigation systems that irrigate during short periods of rain, irrigation during an extended period of heavy rain is unlikely because it is uneconomical and could cause crop damage from excessive water. In other cases, reported daily irrigation volumes ranged over three orders of magnitude at a single location. At one farm, average daily applications of 2,000-3,000 gallons per day (gal/d) were interspersed with short application periods of $1,000,000 \mathrm{gal} / \mathrm{d}$. Some sites reported irrigation only on the first or last day of each month. In these cases, it is likely that a monthly irrigation volume was estimated but reported on a single day for convenience. In Virginia, some sites reported irrigation rates of over 30 in. per month on a crop, even during months with average rainfall. In other locations, estimates of monthly irrigation water use are identical from one year to the next. Although these inconsistencies might be real, the data more likely reflect reporting errors that can be attributed to lack of metering or concern in what is reported. Accurate information about the area irrigated, crop type, and irrigation method could help determine the validity of reported irrigation water use in these cases.

In 2003, Georgia required all permitted irrigation water use to be metered (Georgia General Assembly, 2003), and meters were installed from 2004 to 2009. Since 2004, annual metered irrigation volumes are collected from all permitted irrigation sites in Georgia. In addition, daily metered data are collected at a subset of irrigation sites across the state. Although metered data are more accurate than estimated data, several conditions could cause incorrect readings. For example, after the pump is shut off, negative air pressure in the well or in the supply pipe can cause the meter impeller to operate in reverse and can artificially decrease the meter reading. Conversely, the recorded irrigation volume could be larger than the actual volume because of positive air pressure in the distribution line caused by rising groundwater levels after a pump has been shut off. A previous analysis of annual Georgia irrigation water-use data at over 4,000 metered sites determined that erroneous meter measurements were present at about 2.5 percent of the sites, resulting in a 38 percent overestimation of statewide mean irrigation volume (Torak and Painter, 2011). These sites were removed from the analysis, but less obvious metering errors could be a factor in the reported irrigation use. Despite potential uncertainties related to meter malfunctions, the daily and weekly metered data from Georgia are considered to be the most accurate of all the data available for this study. For this reason, the daily and weekly metered irrigation volume data from Georgia in 2009 and 2010 were used to develop the logistic regression model and to assess the crop-water-demand models.

\section{Data Stratification by Type of Crop}

Irrigation data were stratified by crop type in order to develop predictive models for specific crops. The Georgia irrigation data consisted of daily metered water-use volumes at 55 sites in southern and eastern Georgia from March 1, 2009, to December 31, 2009, and weekly metered water-use volumes at 76 sites in southwestern Georgia from May 9, 2010, to October 24, 2010 (fig. 1). Irrigation systems in Georgia are primarily center pivot, and each metered site provided water to only one field. It was assumed that only one crop was grown during the growing season; however, double cropping, in which two crops are grown in succession during one summer growing season, is a common practice in southern Georgia. It was unknown at which metered sites, if any, double cropping took place. In addition, irrigated acreage was not always reported, and crop type was typically not reported. This information then had to be determined from published geospatial data as described below.

Two geospatial datasets were used to supplement the Georgia irrigation data by providing additional information on the irrigated acreage and crop type. The Georgia irrigated lands spatial data layer maps the area of irrigated fields in Georgia from 2006 to 2008 (Hook and others, 2009). This data layer was used to confirm the reported irrigated acreage. When the reported irrigated area did not reasonably match the irrigated area from the spatial data layer, the data were removed from further analysis. The Georgia irrigated lands spatial data layer also provided some crop-type information such as pecans and turf; however, most fields are labeled only as rotation crops, which consist mostly of corn, cotton, peanuts, and soybeans in Georgia. Geospatial data from the Cropland Data Layer (CDL) (U.S. Department of Agriculture, National Agricultural Statistics Service, 2009b, 2010) were used extensively to determine the specific crop being grown in each irrigated field during the year the data were reported. The CDL has crop-specific and other land-cover information developed from composite satellite imagery at a 30-meter resolution. The CDL can identify crop types for doublecropped fields with a summer crop followed by a winter crop, but it does not identify both crop types in fields with two summer crops, as is common in southern Georgia. Fields with two or more summer crops are classified in the CDL as only having one crop type.

The Georgia irrigated lands spatial data layer and the CDL were overlain with the georeferenced position of the irrigation meters to match individual metered data from 2009 and 2010 to specific irrigated fields and crop types (fig. 2). Center pivot systems are the most common type of irrigation systems used in Georgia. Fields irrigated by center pivot irrigation were easily identified in the CDL because of their round shape and most cases could be associated with the metered data because the meter location is typically in the center of the field (point A, fig. 2). In some cases, the meter was outside a field or between several nearby fields. In these cases, the irrigated acreage, if reported, was matched to the 

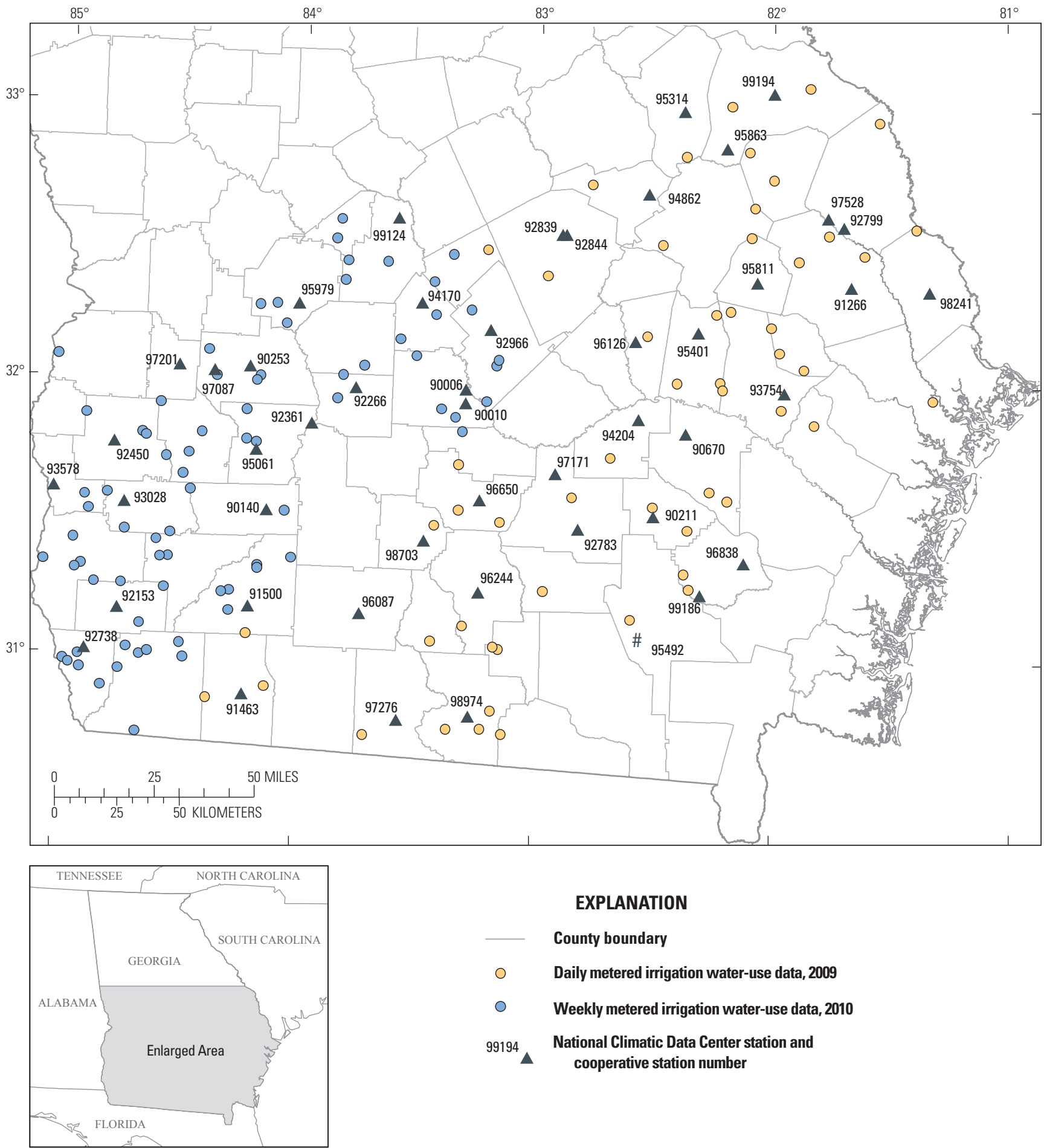

\section{EXPLANATION}

\section{County boundary}

○ Daily metered irrigation water-use data, 2009

Weekly metered irrigation water-use data, 2010

99194 National Climatic Data Center station and cooperative station number

Base maps from U.S. Geological Survey digital coverages, State Plane Coordinate System, NAD 83

Figure 1. Locations of irrigation sites with daily and weekly irrigation data from 2009 and 2010 and National Climatic Data Center climate stations in southern Georgia. 


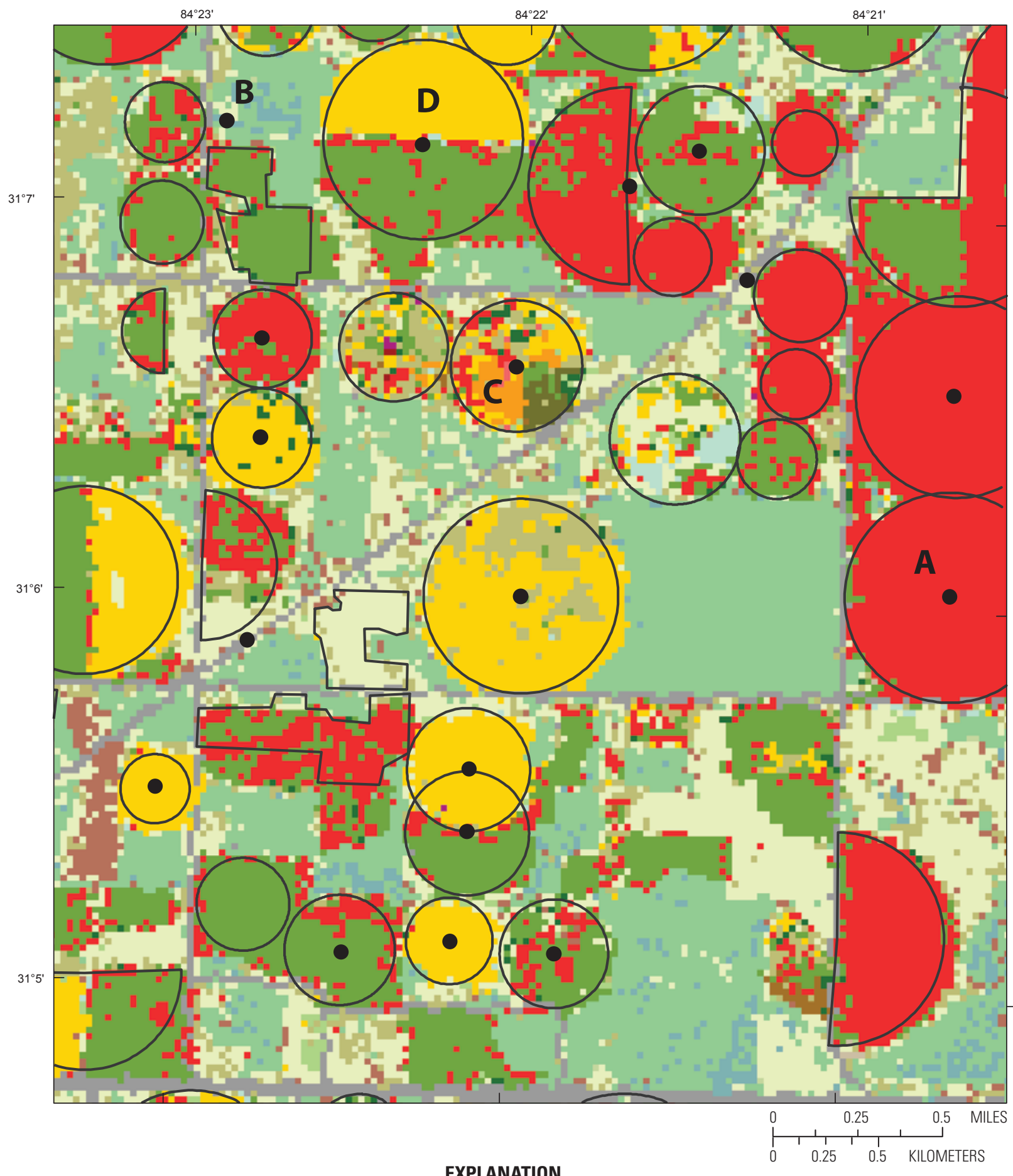

EXPLANATION

Cropland Data Layer (2010)

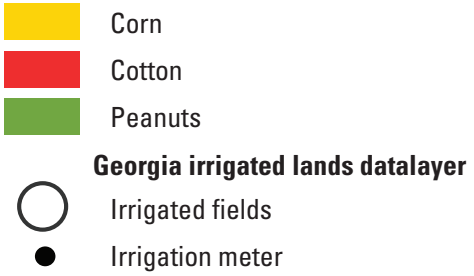

Types of metered conditions

A Meter easily identified with a specific area and crop

B Meter not readily associated with an irrigated field

C Indistinguishable crop type

D Meter associated with multiple crops

Figure 2. Example overlay of meter locations with Cropland Data Layer and Georgia irrigated lands geospatial dataset. Cropland data layer from U.S. Department of Agriculture, National Agricultural Statistics Service (2010). 
crop type in the nearby field(s) having the same acreage, or the data were removed from further analysis (point B, fig. 2). Roughly, half the reported irrigation data in Georgia did not report corresponding irrigated acreage. If no irrigated acreage was reported and the meter could not be associated with a particular field, data for that meter site were not used in the analysis. Data from 31 sites were removed from the analysis for this reason.

After matching each metered data point with a field, the CDL was used to identify the crop being grown for the appropriate year. In some cases, more than one crop is associated with a meter (points $C$ and $D$, fig. 2). In these cases, the crop type cannot be identified (fig. 2, point C) or the field is split by different crops (fig. 2, point D) that may be irrigated at different rates or frequencies, or both. These sites were screened from further analysis.

A total of 36 sites with daily or weekly metered data from 2009 and 2010 could be matched to an irrigated field and a single crop type. This screened data were composed of 6 corn, 6 peanut, 6 soybean, and 18 cotton fields. Although climatic conditions were similar between the sites, the magnitude and frequency of monthly irrigation varied appreciably between crop types (fig. 3) because of different water demands during different parts of the growing cycle.

Turf grass is an important crop in many mid-Atlantic and northeastern states. In Rhode Island, turf farms represent over 60 percent of all irrigated farmland (U.S. Department of Agriculture, National Agricultural Statistics Service, 2009a). Daily metered turf-grass irrigation volumes and acreage were collected by the USGS at eight turf farms in Rhode Island during 2000 to 2004 for basin studies by Zarriello and Bent (2004) and Bent and others (2009).Turf-farm irrigation rates in Rhode Island ranged from 0.3 to 11 inches per year (in/yr); the average was $3.6 \mathrm{in} / \mathrm{yr}$. Rates peaked in 2002 as result of low precipitation during the months of July and August.

\section{Irrigation Estimation Methods}

Irrigation water use was estimated by using two different methods. One method used irrigation data from Georgia for corn, cotton, peanut, and soybean crops to develop logistic regression models that predict the likelihood of irrigation for these crops. A logistic regression equation previously developed for turf farms and golf courses in Rhode Island (Zarriello and Bent, 2004; Bent and others, 2009) was also used in this study. The second method used a soil water balance and crop water demand to estimate irrigation needs and was applied to the same crops. Results from both modeling approaches were compared to each other and to independent reported data.

\section{Logistic Regression}

Logistic regression is a statistical technique that predicts the probability of an event occurring on the basis of one or more explanatory variables. Logistic regression models were first applied in a basin study in Rhode Island by Zarriello and Bent (2004) to estimate irrigation water use at unmetered sites and to estimate irrigation water use over time on the basis of past climate conditions. In this study, regression equations for daily turf irrigation in Rhode Island by Zarriello and Bent (2004) were reexamined with an expanded dataset, and new logistic regression equations were developed for Georgia corn, cotton, peanut, and soybean crops to predict the probability of irrigation taking place during a particular week on the basis of weekly antecedent climate conditions. Initial attempts to develop a daily irrigation model for Georgia crops produced poor results because of the reduced number of sites with daily data and because irrigation systems generally require more than a day to completely irrigate the full areal coverage of a field. Weekly equations were developed by using a suite of climate variables and the metered irrigation data from Georgia from 2009 and 2010 during the months of April through October. Weekly application rates were determined from the mean reported irrigation volumes by crop.

\section{Turf Irrigation in Rhode Island}

Zarriello and Bent (2004) developed the following logistic regression equation for predicting daily irrigation for turf farms and golf courses in Rhode Island by using metered irrigation data and climate data collected during the 2000 and 2001 growing seasons:

$$
P=\frac{\mathrm{e}^{(-5.6791+4.8271 \times \mathrm{PET} 2+1.5760 \times \mathrm{PET} 20-1.2070 \times \mathrm{PRCP} 10)}}{1+\mathrm{e}^{(-5.6791+4.8271 \times \mathrm{PET} 2+1.5760 \times \mathrm{PET} 20-1.2070 \times \mathrm{PRCP} 10)}},
$$

where

$$
\begin{aligned}
P & =\text { probability of daily irrigation; } \\
\mathrm{e} & \text { base of the natural logarithm, equal to } \\
& \text { approximately } 2.7183 ; \\
= & \text { total potential evaporation volume, in } \\
& \text { inches, during the previous } 2 \text { days; } \\
\text { PET2 } & \text { total potential evaporation volume, in } \\
\text { PET20 } & \text { inches, during the previous } 20 \text { days; and } \\
\text { PRCP10 } & \text { total precipitation, in inches, during the } \\
& \text { previous } 10 \text { days. }
\end{aligned}
$$

The equations apply to turf irrigation during May 1 through October 31 and golf-course irrigation during April 16 through November 15 . The probability of irrigation predicted by the equations ranges from 0 to 1 . A cutpoint is the probability threshold for predicting when irrigation is or is not used. Computed probabilities equal to and higher than the cutpoint represent days when irrigation is predicted and those less than the cutpoint predict days of no irrigation. The procedure for determining optimal cutpoints for a logistic regression equation is discussed later in this report. A cutpoint of 0.34 was determined by Zarriello and Bent (2004); however, with the additional turf-irrigation data from Bent and others (2009), a cutpoint of 0.50 was found to apply and was used in this study. 

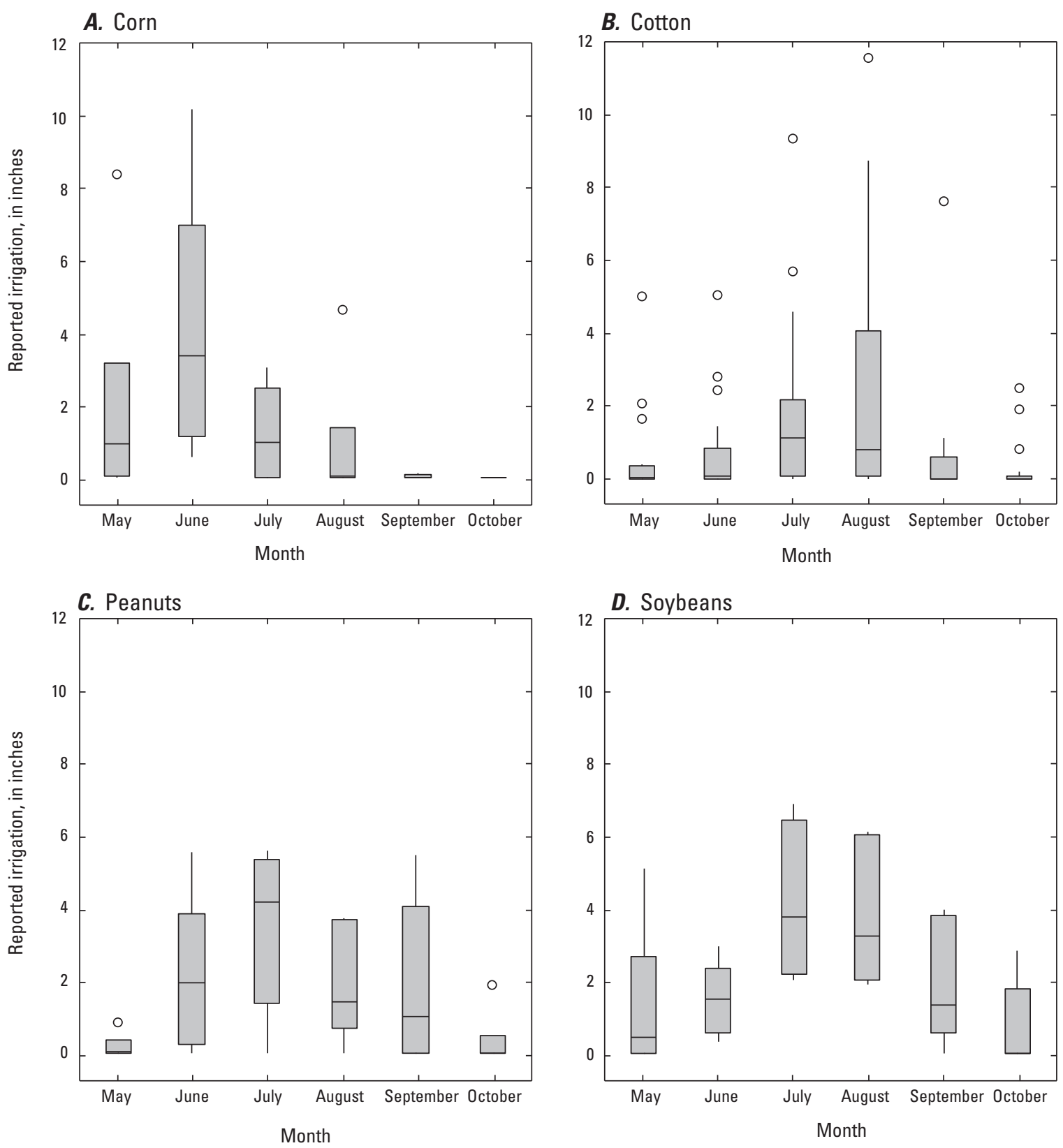

\section{EXPLANATION}

O Outlier

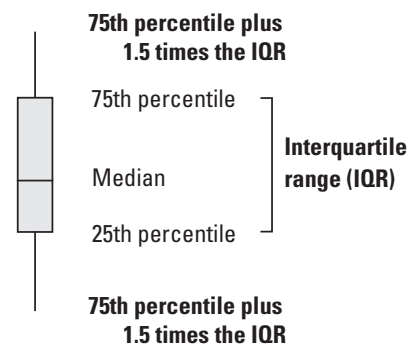

Figure 3. Monthly irrigation water use during 2009 and 2010 at $A, 6$ corn; $B, 18$ cotton; $C, 6$ peanut; and $D, 6$ soybean fields in southern Georgia. 
The turf farms include the three metered turf farms used in the equation development by Zarriello and Bent (2004) and the six additional turf farms metered by Bent and others (2009). Equation 1 accurately predicted the days when irrigation took place 83 percent of the time at the nine turf farms with metered data from 2000 to 2004.

Total annual (May through October) irrigation depth was determined by multiplying the number of days when irrigation was predicted from the logistic regression equation by the mean application rate. The average irrigation application rate on Rhode Island turf farms was about 0.1 inch per day (Bent and others, 2009). Estimates of annual turf-farm irrigation by the regression equation matched average reported annual irrigation (fig. 4, table 2) reasonably well with a root mean squared error (RMSE) of 1.0 in. Model estimates do not vary spatially because only one central climate station was used in the analysis. Average precipitation during the growing season was 22.9 in.; the minimum was $20.1 \mathrm{in}$. in 2000 and the maximum was 25.6 in. in 2003. This equation was not evaluated for other areas in the northeast because of the lack of irrigation water-use data; however, the equation is considered a reasonable tool for estimating irrigation water use for turf farms and golf courses in the region on the basis of verification tests discussed later in the report.

\section{Agricultural Crop Irrigation in Georgia}

Logistic regression equations that predict irrigation for corn, cotton, peanut, and soybean crops were developed by using the metered irrigation data in Georgia. Precipitation, PET, and crop-specific potential evapotranspiration (CPET) during several antecedent periods were tested for use as explanatory variables in the logistic equations. Daily precipitation and temperature were obtained from the National Oceanic and Atmospheric Administration (NOAA) National Climatic Data Center (NCDC) for 24 stations for 2009 and 2010 (fig. 1). PET was calculated from the temperature data by using the Hamon method (Hamon, 1961), which is based on minimum and maximum daily air temperature and potential hours of sunshine computed as a function of latitude. All daily precipitation and PET volumes were aggregated into 1-, 2-, and 3-week totals.

In addition to reference PET, CPET was calculated for each of the four crops in Georgia. Because equations for calculating PET are developed for a reference crop, usually a hay crop such as alfalfa, they can be unreliable when used for agricultural crops such as corn, cotton, peanuts, and soybeans, which have different growth patterns and water demands. CPET estimates the evapotranspiration of a specific crop and

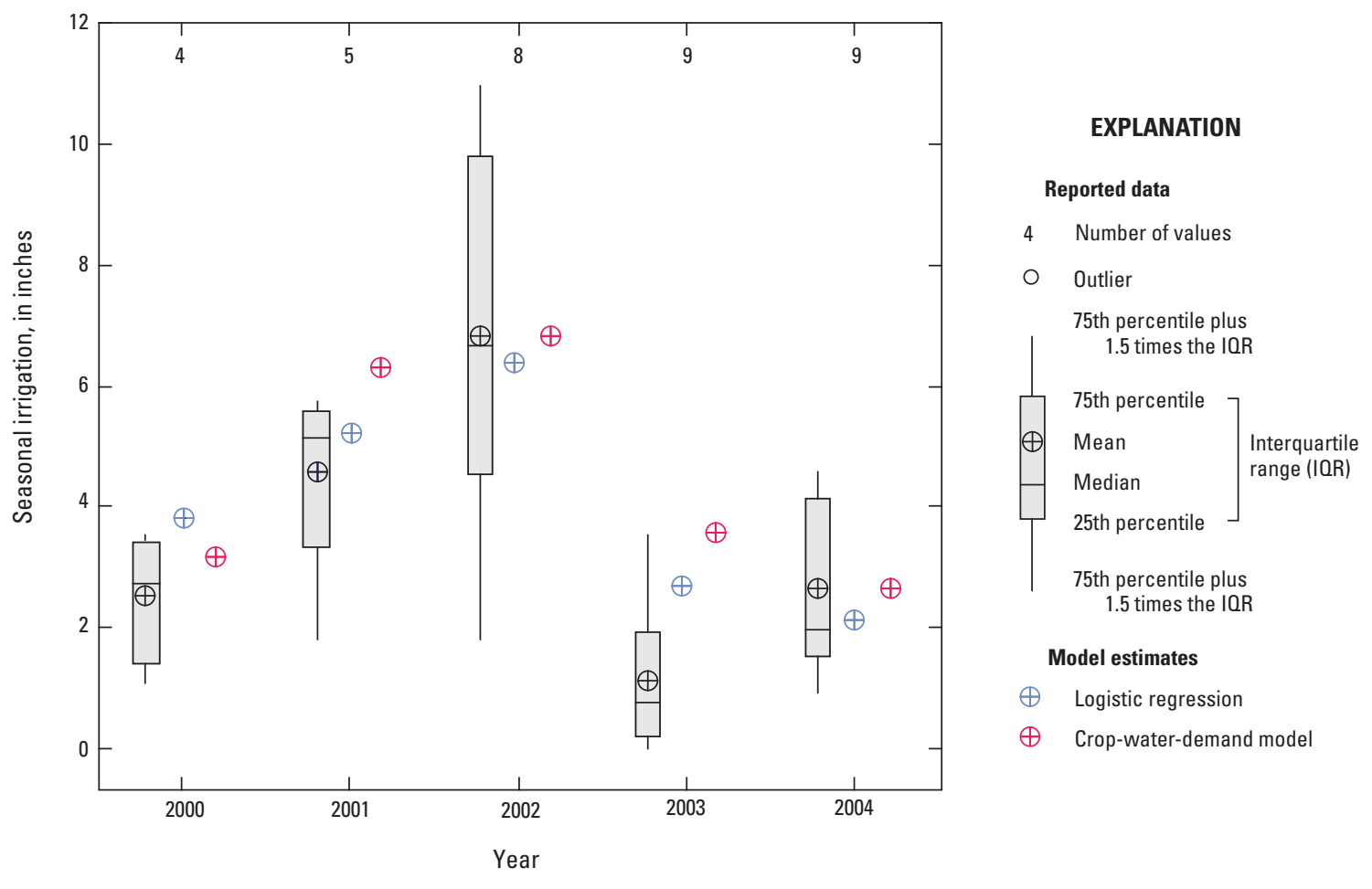

Figure 4. Reported data and model estimates of annual irrigation from 2000 to 2004 at nine turf farms in Rhode Island. 
Table 2. Reported data and model estimates of annual irrigation for turf farms during 2000 to 2004 in Rhode Island, and corn, cotton, peanut, and soybean farms during 2009 and 2010 in southern Georgia.

[RMSE, root mean squared error]

\begin{tabular}{|c|c|c|c|c|}
\hline \multirow[t]{2}{*}{ Year } & \multirow[t]{2}{*}{ Number of sites } & \multicolumn{3}{|c|}{$\begin{array}{l}\text { Average irrigation, } \\
\text { in inches per year }\end{array}$} \\
\hline & & Observed & Crop-water-demand model & Logistic regression model \\
\hline \multicolumn{5}{|c|}{ Corn } \\
\hline 2009 & 3 & 6.2 & 5.5 & 8.6 \\
\hline 2010 & 3 & 10.1 & 8.3 & 8.6 \\
\hline Mean & & 8.1 & 6.9 & 8.6 \\
\hline RMSE & & & 1.4 & 2.0 \\
\hline \multicolumn{5}{|c|}{ Cotton } \\
\hline 2009 & 5 & 3.6 & 4.8 & 3.2 \\
\hline 2010 & 13 & 3.9 & 7.5 & 3.8 \\
\hline Mean & & 3.8 & 6.2 & 3.5 \\
\hline RMSE & & & 2.7 & 0.3 \\
\hline \multicolumn{5}{|c|}{ Peanuts } \\
\hline 2009 & 1 & 9.3 & 4.6 & 11.2 \\
\hline 2010 & 5 & 12.8 & 9.8 & 13.4 \\
\hline Mean & & 11.0 & 7.2 & 12.3 \\
\hline RMSE & & & 3.9 & 1.5 \\
\hline \multicolumn{5}{|c|}{ Soybeans } \\
\hline 2009 & 5 & 9.7 & 8.3 & 10.7 \\
\hline 2010 & 1 & 11.1 & 12.5 & 11.4 \\
\hline Mean & & 10.4 & 10.4 & 11.1 \\
\hline RMSE & & & 1.4 & 0.7 \\
\hline \multicolumn{5}{|c|}{ Turf } \\
\hline 2000 & 4 & 2.5 & 3.4 & 3.8 \\
\hline 2001 & 5 & 4.6 & 6.7 & 5.2 \\
\hline 2002 & 8 & 6.8 & 6.9 & 6.4 \\
\hline 2003 & 9 & 1.1 & 3.9 & 2.7 \\
\hline 2004 & 9 & 2.7 & 2.8 & 2.1 \\
\hline Mean & & 3.5 & 4.7 & 4.0 \\
\hline RMSE & & & 1.6 & 1.0 \\
\hline
\end{tabular}

is computed by multiplying the PET by a crop coefficient. The CPET assumes there is no water limitation, and it is not the actual crop evapotranspiration.

Crop coefficients have been determined for most crops and vary throughout the growing season. Coefficients are usually lowest in the early stages of growth when leaf area is small and highest in the middle of the growing season during fruit development and vary regionally because of differences in soil properties and climate. Crop coefficients for corn and cotton from the University of Georgia Cooperative Extension (Harrison, 2009a) vary seasonally from about 0.2 to 1.1 (fig. 5A and B). Regional estimates of crop coefficients for soybeans and peanuts were not available for Georgia and were from the Food and Agriculture Organization of the United Nations (FAO) (Food and Agriculture Organization of the United Nations, Water Development and Management Unit, 2011). Soybean and peanut crop coefficients varied seasonally from about 0.4 to 1.1 (figs. 5C and D). Crop coefficients are reported relative to the number of days after planting. Average planting dates for the four Georgia crops from the National Agricultural Statistics Service (U.S. Department of Agriculture, National Agricultural Statistics Service, 1997) were used to assign CPET values to specific calendar days. CPET volumes for each crop also were aggregated to 1-, $2-$, and 3-week totals for use as explanatory variables in the logistic equations. 

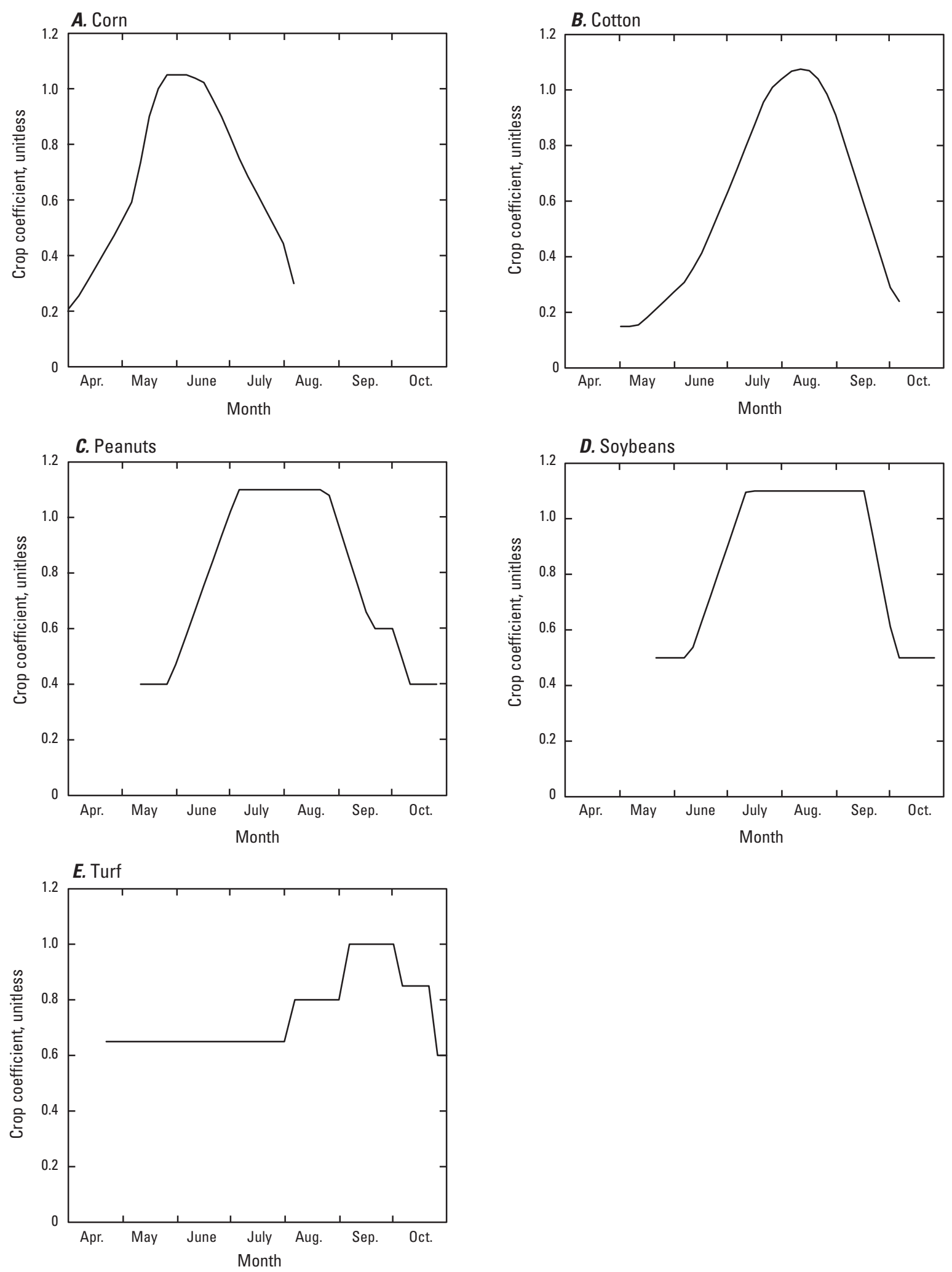

Figure 5. Crop coefficients for $A$, corn; $B$, cotton; $C$, peanuts; and $D$, soybeans for Georgia and $E$, turf for Rhode Island. 
Logistic regression models were developed with the SAS software package (SAS Institute, Inc., 1995, p. 51-65). Model selection was performed with the best subsets method and avoided simultaneous use of highly correlated variables. This model-selection technique fits equations for all possible combinations of explanatory variables and chooses the final model based on goodness-of-fit statistics. PET and CPET variables of all antecedent periods were highly correlated with each other. In addition, precipitation variables of different antecedent periods were also highly correlated with each other but were not correlated (or inversely correlated) with PET or CPET variables. Highly correlated explanatory variables were not used together in any equation to avoid covariance, which can cause unreliable model coefficient estimates (Helsel and Hirsch, 1992). Candidate equations for each crop type were evaluated for goodness of fit by using the Akaike Information Criteria (AIC) and the Hosmer-Lemeshow test (Hosmer and Lemeshow, 2000). For a given dataset, the AIC indicator is used to compare candidate models; the lower values indicate better-fitting models. The Hosmer-Lemeshow test is specific to logistic regression and compares the predicted probabilities to observed responses to identify whether there is significant bias in the model. A Hosmer-Lemeshow test $p$-value less than 0.1 indicates a lack of fit in the model. Final logistic models were chosen based on goodness-of-fit statistics and were all statistically significant at the 95-percent confidence level compared to the null model (table 3 ). The best-fit logistic regression models predicting the probability of irrigation during a week for corn, cotton, peanut, and soybean crops are:

- Corn

$$
P=\frac{\mathrm{e}^{(-1.8569+1.1336 \times \text { CPET } 2)}}{1+\mathrm{e}^{(-1.8569+1.1336 \times \text { CPET } 2)}}
$$

- Cotton

$$
P=\frac{\mathrm{e}^{(-1.3894+0.6428 \times \mathrm{CPET} 2-0.3551 \times \mathrm{PRCP} 1)}}{1+\mathrm{e}^{(-1.3894+0.6428 \times \text { CPET2 }-0.3551 \times \mathrm{PRCP} 1)}}
$$

- Peanuts

$$
P=\frac{\mathrm{e}^{(-1.9986+1.3443 \times \text { CPET } 2-0.4267 \times \text { PRCP } 1)}}{1+\mathrm{e}^{(-1.9986+1.3443 \times \text { CPET } 2-0.4267 \times \text { PRCP } 1)}}
$$

- Soybeans

$$
P=\frac{\mathrm{e}^{(-2.9786+2.4654 \times \mathrm{CPET} 1)}}{1+\mathrm{e}^{(-2.9786+2.4654 \times \mathrm{CPET} 1)}}
$$

where

$$
\begin{aligned}
P \quad= & \text { probability of irrigation during any week } \\
& \text { between April } 1-\text { October } 31 ;
\end{aligned}
$$
CPET1
$=$ total crop potential evapotranspiration, in inches, during the week for which irrigation is being predicted;
CPET2 = total crop potential evapotranspiration, in inches, during the week for which irrigation is being predicted and the previous week; and
PRCP1 = total precipitation, in inches, during the week for which irrigation is being predicted.

Each crop uses a measure of antecedent CPET, but the coefficients and antecedent period vary by crop. Cotton and soybean equations also use antecedent precipitation with different coefficients for each crop.

The predicted probability of irrigation $(P)$ can range from near 0 to 1 ; values closer to 1 indicate a higher likelihood of irrigation. Each equation was analyzed to determine the most appropriate cutpoint for predicting irrigation use. The cutpoint is determined iteratively by comparing model outcomes with reported data over a range of potential cutpoint values (Hosmer and Lemeshow, 2000). For each cutpoint, the number of false positives and false negatives is determined. A false positive occurs when there is a prediction of irrigation when no irrigation was reported. A false negative occurs when there is a prediction of no irrigation when irrigation was reported. The optimal cutpoint for an equation balances the number of false negative and false positive values. Optimal cutpoints were about the same for corn and cotton (0.42 and 0.41 , respectively) but were higher for peanuts $(0.56)$ and soybeans (0.46).

The overall accuracy of equations was determined by comparing weekly predictions of the occurrence of irrigation to reported data and determining the percentage of correct predictions. Equation accuracies were 70 percent for corn, 66 percent for cotton, and 72 percent for peanuts and soybeans; other metrics of the goodness of fit between predicted and reported weekly irrigation in Georgia are summarized in table 3. In general, the logistic regression equations (eqs. 2-5) predict the occurrence of weekly irrigation for these crops reasonably well with a balance of false positive and false negative predictions. False positives and negatives were predicted about 14 to 17 percent of the time for corn and cotton irrigation and about 13 to 14 percent of the time for peanut and soybean irrigation.

Total weekly irrigation water use was estimated from results of the logistic regression equations and the median weekly application rate determined for each month and crop type from the Georgia data (table 4). Mean annual irrigation was estimated by multiplying the weekly application rate by the number of weeks of irrigation during each month of the growing season. Annual irrigation water-use estimates from the regression equations had RMSEs of 2.0, 0.3, 1.5, and 0.7 in. for corn, cotton, peanuts, and soybeans, respectively (table 2). Logistic regression estimates of annual irrigation match mean annual reported irrigation for the four crop types reasonably well; however, the variability between sites was not well represented with the logistic approach (fig. 6). 


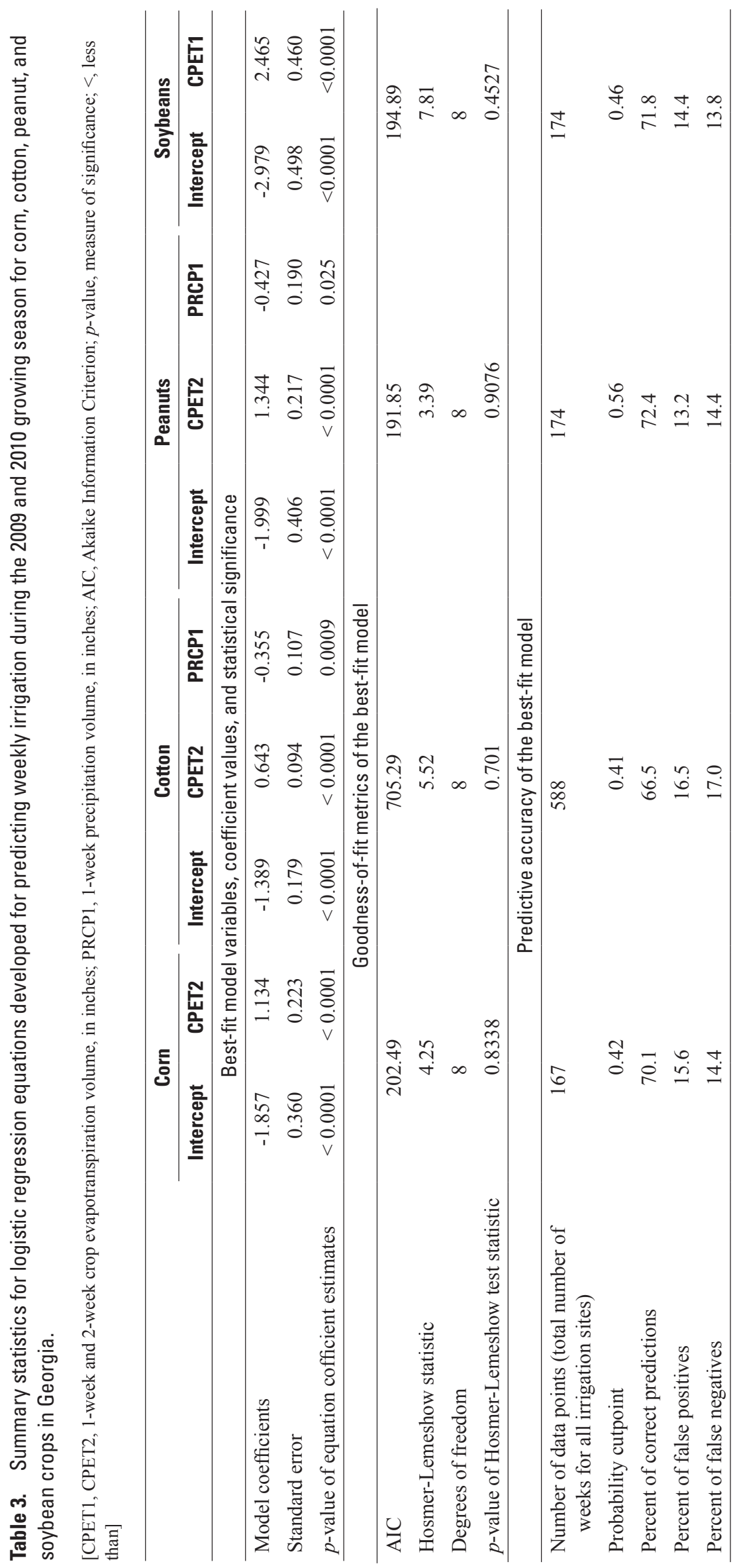


Table 4. Seasonal median irrigation (May to October) during 2009 and 2010 for 6 corn, 18 cotton, 6 peanut, and 6 soybean sites in Georgia.

\begin{tabular}{lllcccc}
\hline \multirow{2}{*}{ Crop } & \multicolumn{7}{c}{$\begin{array}{c}\text { Median growing-season irrigation rate (May to October), } \\
\text { in inches per week }\end{array}$} \\
\cline { 2 - 7 } & May & June & July & August & September & October \\
\hline Corn & 0.40 & 0.97 & 0.77 & 0.07 & 0.03 & 0.02 \\
Cotton & 0.08 & 0.35 & 0.57 & 0.40 & 0.16 & 0.05 \\
Peanuts & 0.66 & 0.72 & 1.03 & 0.71 & 0.72 & 0.45 \\
Soybeans & 0.11 & 1.16 & 1.32 & 0.76 & 1.18 & 0.90 \\
\hline
\end{tabular}
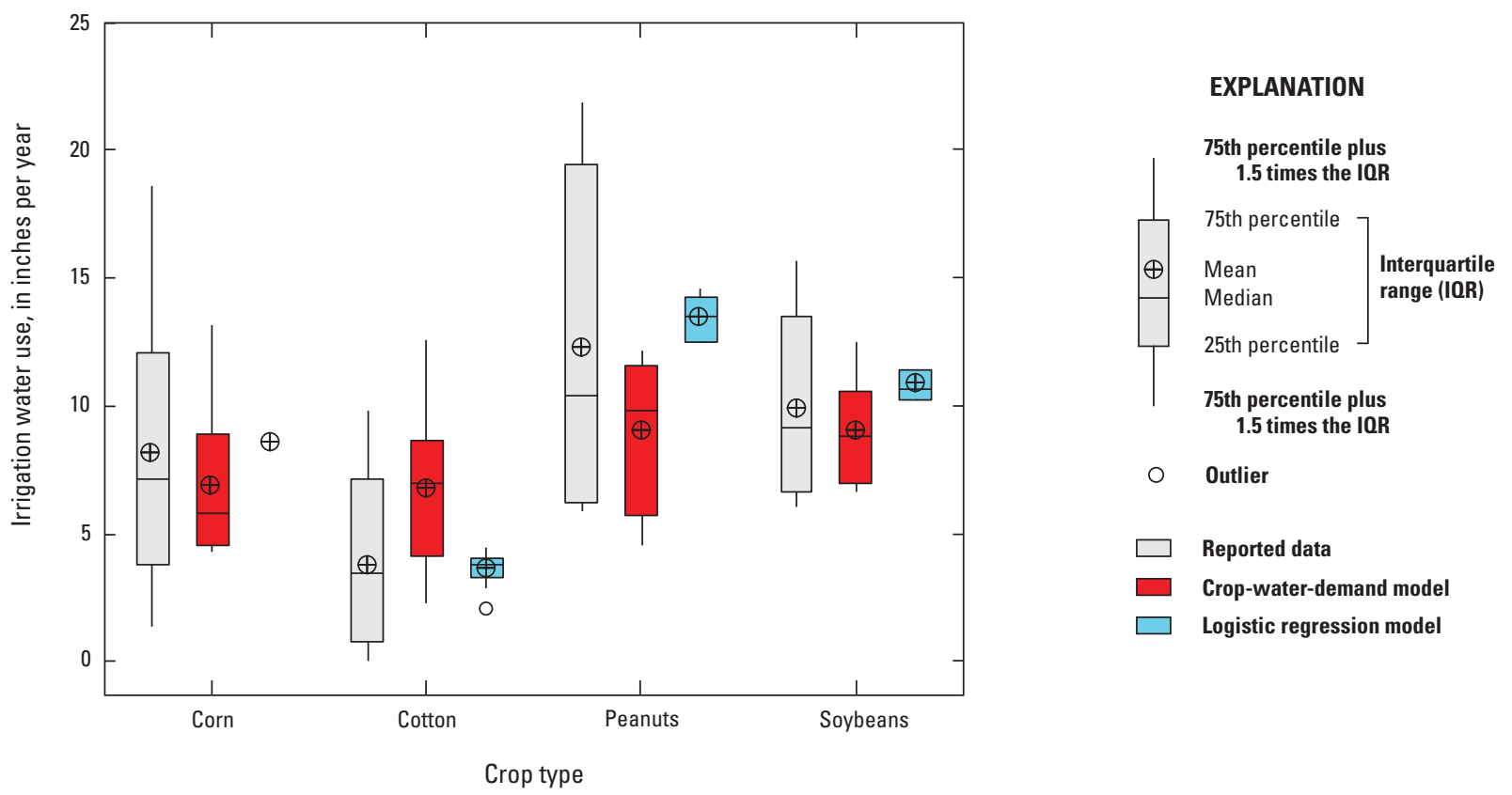

Figure 6. Reported data and model estimates of 2009 and 2010 seasonal irrigation (May through October) for corn, cotton, peanut, and soybean crops in Georgia.

Despite large differences in total seasonal precipitation between sites (growing-season precipitation totals ranged from 19.5 to 39.1 in.), logistic regression estimates of total irrigation were not highly variable, likely as a result of the weekly time step used in the model. Equations at a weekly time scale can only produce a limited number of values for a growing season. For example, in any month, the model can produce one of five results - no irrigation or irrigation for 1, 2,3 , or 4 weeks, and because the application rate is constant each week, the final predicted irrigation volume for the month can be only one of five values, despite potentially large differences in antecedent climate variables. Thus, the temporal scale of the equations inherently limits the sensitivity of the model to variations in climate. Additionally, reported weekly application rates are highly variable, ranging from 0.01 to
1.05 in. per week, because irrigation can be used from between 1 to 7 days during the week. The use of a median application rate adds uncertainty to the weekly volume estimate because it does not account for the number of irrigated days per week. Equations built on a daily time step are more sensitive to short-term weather patterns and are better able to account for site-to-site variability in irrigation due to local precipitation patterns. Reported daily application rates are also less variable than weekly application rates because the total volume per acre of water that can be applied in 1 day is much less than can be applied in 1 week. The collection of additional daily irrigation water-use data could help refine the temporal scale and application rates of logistic-regression-based irrigation models in future studies. 


\section{Crop-Water-Demand Models}

Crop-water-demand models are deterministic models that use mathematical representations of physical processes to estimate the state of the system during a given time period. These models are fundamentally different from statistical models such as logistic regression that use the correlation patterns in the observed data to derive empirical relations between explanatory variables and observed outcomes. Cropwater-demand models for irrigation keep track of soil moisture by accounting for daily soil water inputs, such as precipitation and irrigation, and daily soil water outflows from evapotranspiration. When soil water is depleted such that the crop water demand cannot be fulfilled, the model calculates the amount of irrigation needed to satisfy the deficit.

A daily crop-water-demand model was set up following guidelines from the University of Georgia Cooperative Extension (Harrison, 2009a) and Colorado State University Cooperative Extension (Andales and others, 2011) to estimate crop irrigation volumes in Georgia and turf irrigation volumes in Rhode Island. The crop-water-demand model has three steps. First, the daily soil water deficit is calculated as the difference between the maximum soil water content and the current soil water content. Next, the soil water deficit is compared to the maximum allowable deficit for a crop, which determines whether irrigation is needed. Finally, if the water deficit is greater than the maximum allowable deficit for a crop, irrigation is applied at a rate proportional to the water deficit. The daily soil-water content is computed as

$$
\operatorname{Sin}_{t}=S_{t-1}+P_{t}-\operatorname{PET}_{t} \times \mathrm{cf}_{t}
$$

where

$$
\begin{array}{cl}
\operatorname{Sin}_{\mathrm{t}} & \text { soil water content prior to irrigation for day } \\
& \mathrm{t}, \text { in inches; } \\
\mathrm{S}_{\mathrm{t}-1} & =\text { soil water content after irrigation for the } \\
& \text { previous day, in inches; } \\
\mathrm{P}_{\mathrm{t}} & =\text { precipitation for day } \mathrm{t}, \text { in inches; } \\
\mathrm{PET}_{\mathrm{t}} & \text { potential evapotranspiration for day } \mathrm{t}, \text { in } \\
& \quad \text { inches; and } \\
\mathrm{cf}_{\mathrm{t}} & =\text { crop coefficient. }
\end{array}
$$

The maximum soil water (Smax) is the product of the soil water capacity and the effective root depth. Soil water capacity is determined from soil surveys and was set at $0.12 \mathrm{in}$. of water per inch of soil. This is the value recommended by the University of Georgia Cooperative Extension (Harrison, 2009a). The root depth was set at 5 in. at planting date and increased to a maximum of 24 in. over the growing period as suggested in the guidance document. For each day, the water deficit is computed as the difference between the Smax and the soil water content $\left(\operatorname{Sin}_{t}\right)$

$$
\mathrm{WD}_{\mathrm{t}}=\operatorname{Smax}_{\mathrm{t}}-\mathrm{Sin}_{\mathrm{t}}
$$

where

$$
\begin{aligned}
\mathrm{WD}_{\mathrm{t}} & =\text { water deficit for day } \mathrm{t}, \text { in inches; } \\
\operatorname{Smax}_{\mathrm{t}} & \text { maximum available soil water for day } \mathrm{t}, \\
& \text { in inches; and } \\
\operatorname{Sin}_{\mathrm{t}} & \text { soil water content prior to irrigation for day } \\
& \mathrm{t}, \text { in inches. }
\end{aligned}
$$

$\operatorname{Sin}_{t}$ accounts for the water content from the irrigation for the previous day.

Plants can withstand small water deficits (draught tolerance) without yield reduction so keeping soils at maximum saturation is usually not necessary. However, excessive depletion of soil water reduces crop growth and yield and at some point will eventually destroy the crop. Management allowed depletion (MAD) is the percentage of the Smax that can be depleted before irrigation is needed. MAD values are typically set to 50 percent of Smax, but cropspecific values and varying monthly values are found in cropproduction guidelines by university cooperative extensions, USDA, or other agricultural agencies (Al-Kaisi and Bromer, 2009; U.S. Bureau of Reclamation, 2012). MAD is multiplied by the Smax to calculate the maximum allowable water deficit $\left(\mathrm{WD}_{\mathrm{MAD}}\right)$. Irrigation is needed whenever the daily water deficit exceeds the maximum allowable deficit. In this study, crop MAD values were set at a constant value of 50 percent.

$$
\mathrm{WD}_{\mathrm{MAD}}=\mathrm{MAD} \times \operatorname{Smax}_{\mathrm{t}}
$$

where

$$
\begin{aligned}
\mathrm{WD}_{\mathrm{MAD}}= & \text { maximum allowable water deficit, in inches; } \\
\mathrm{MAD}= & \text { managed allowable depletion, in percent; } \\
& \text { and } \\
\text { Smax }_{\mathrm{t}}= & \text { maximum available soil water, in inches. }
\end{aligned}
$$

The volume of irrigation water applied is proportional to the water deficit and can range from a minimum required to increase the soil water to the maximum allowable water deficit $\left(\mathrm{WD}_{\mathrm{MAD}}-\mathrm{Sin}_{\mathrm{t}}\right)$ to a maximum that completely replenishes soil water to saturation ( $\mathrm{WD}_{\mathrm{t}}$ ). Use of the maximum allowable water deficit as the application volume in the model results in high irrigation volumes but less frequent applications. Actual application rates are determined by many things including the pumping capacity of the irrigation system, the farmer's expectation of future rainfall, and the perceived water deficit. This study used the minimum application rate $\left(\mathrm{WD}_{\mathrm{MAD}}-\mathrm{Sin}_{\mathrm{t}}\right)$ because this rate most closely matched reported daily application rates in Georgia. The crop water models with application rates equal to the minimum application rate $\left(\mathrm{WD}_{\mathrm{MAD}}-\mathrm{Sin}_{\mathrm{t}}\right)$ accurately predicted the use of irrigation for a given week 60 , 65,78 , and 64 percent of the time for corn, cotton, soybeans, and peanuts, respectively. Estimates of average seasonal irrigation by the crop-water-demand model in 2009 and 2010 had RMSEs of 1.4, 2.7, 3.9, and 1.4 in., respectively (table 2). Over the 2009 and 2010 growing seasons, the crop-waterdemand method was generally less accurate than the logistic method, but the crop-water-demand model estimates of seasonal irrigation better represented the spatial variability than 
the logistic regression estimates. The higher variability in the crop-water-demand model estimates is believed to result from the daily time step of the model compared to the weekly time step used in the logistic models.

A crop-water-demand model was developed to predict turf irrigation in Rhode Island by using published values for the model variables. Crop coefficients ( $\mathrm{cf}_{\mathrm{t}}$ ) ranged from 0.4 in March to 1.0 from June through October (fig. 5) (Aronson and others, 1987; Carrow, 1995). The depth of the effective rooting zone ranged from $5 \mathrm{in}$. at planting to a maximum depth of 12 in. The frequency and magnitude of irrigation on Rhode Island turf farms best matched reported irrigation when the irrigation application rate specified in the model was equal to the maximum allowable deficit $\left(\mathrm{WD}_{\mathrm{MAD}}-\mathrm{Sin}_{\mathrm{t}}\right)$, as was used for Georgia row crops. The crop-water-demand model for turf was able to accurately predict the occurrence of daily irrigation 80 percent of the time in Rhode Island. Estimates of average total irrigation for the years 2000 to 2004 were slightly less accurate than logistic regression estimates; the RMSE was $1.6 \mathrm{in}$. for the crop-water-demand model and 1.0 in. for the logistic model (table 2).

\section{Model Validation and Comparison}

Performance of the two modeling methods was evaluated by using independent sets of reported irrigation data from Georgia and Virginia. Predicted annual irrigation from the logistic regression equations and crop-water-demand models were compared to each other and to reported data. In general, the evaluation of model performance was encumbered by the high variability in reported irrigation rates between sites, despite the fact that climate conditions were similar. High spatial variability is a common characteristic of irrigation water use. Site-to-site variation in irrigation rate can be caused by many factors not related to climate, such as differences in planting dates, water source, irrigation costs, and the risk tolerance of individual farmers. Climate-based irrigation models such as the ones developed for this study are therefore most appropriate for estimating average irrigation water use over a homogeneous climate area such as a county, rather than sitespecific irrigation water use.

\section{Georgia Irrigation}

Metered data reported annually in southwestern Georgia (fig. 7) in 2010 were available at 4,304 sites, of which 3,500 sites also reported irrigated acreage. The data span 18 counties, of which 8 counties were chosen (fig. 7) for model validation on the basis of centrally located climate stations and a range of geographic areas. Crop type was determined by matching the metered locations with a particular field from the Georgia irrigated areas data layer and overlaying the $2010 \mathrm{CDL}$, as described previously. Only sites that had a single crop type within the irrigated area were used in the evaluation. However, double-cropped sites cannot be determined from the CDL, and some of these sites likely had a second crop planted in the field during the growing season. Data screening removed sites with unreasonably high irrigation volumes per unit area (greater than $35 \mathrm{in} / \mathrm{yr}$ ) that may reflect double cropping or incorrectly assigned crop acreage. After determining crop type and removing outliers, the validation dataset consisted of 846 sites including 169 corn, 408 cotton, 263 peanut, and 6 soybean fields. Soybean crops are more common in northern Georgia counties and were limited in the validation data set.

The logistic regression and crop-water-demand models were applied from March 1 to November 30, 2010, to compute annual irrigation volumes to compare to the reported annual volumes (fig. 8). RMSEs for logistic regression models were 6.0, 5.5, 7.0, and 1.0 for corn, cotton, peanut, and soybean models, respectively, and the RMSEs for crop-water-demand models were 5.8, 2.1, 2.6, and 2.4, respectively, for the same crops (table 5). Logistic regression models underestimated mean countywide irrigation water use in most counties for corn, cotton, and peanut crops. In general, the crop-waterdemand model estimates matched mean reported irrigation volumes better than the logistic regression estimates for cotton and peanuts; however, the crop-water-demand model underestimated corn irrigation volumes. Soybean irrigation was adequately predicted by both models; however, the low number of reported soybean irrigation sites make this comparison less certain. Underestimation of irrigation volume, particularly with corn crops, is likely because of the practice of double cropping. For example, cotton or peanut crops are commonly grown after corn crops in southern Georgia; however, these sites may only be classified as corn or peanuts in the CDL. Although this region practices double cropping, little information is available regarding the location or crop composition of double-cropped fields in the currently available data. The logistic regression and crop-water-demand model assume only one crop is planted during the summer growing season. To better estimate irrigation with multiple cropping, more information is needed to characterize the types of crops planted and the frequency of multiple croppings in a region.

\section{Virginia Irrigation}

Monthly irrigation data reported in Virginia from 1999 through 2007 provided an independent data set outside of Georgia and Rhode Island to evaluate the model performance. The data spanned 9 years, of which 2 were relatively wet years (2003 and 2004) and 3 were relatively dry years $(2002,2005$, and 2007). Virginia requires irrigators to report the cumulative water volume for each month that exceeds $1 \mathrm{Mgal}$. However, because Virginia does not require metering, few sites likely use meters to determine their water use. Most of the reported volumes were estimated by multiplying the pumping capacity by the time the pump was running. Many sites do not report the method used to determine the irrigation volume. In addition to irrigation volume, some sites also report the irrigated acreage, crop type, and water source (groundwater or surface water). 

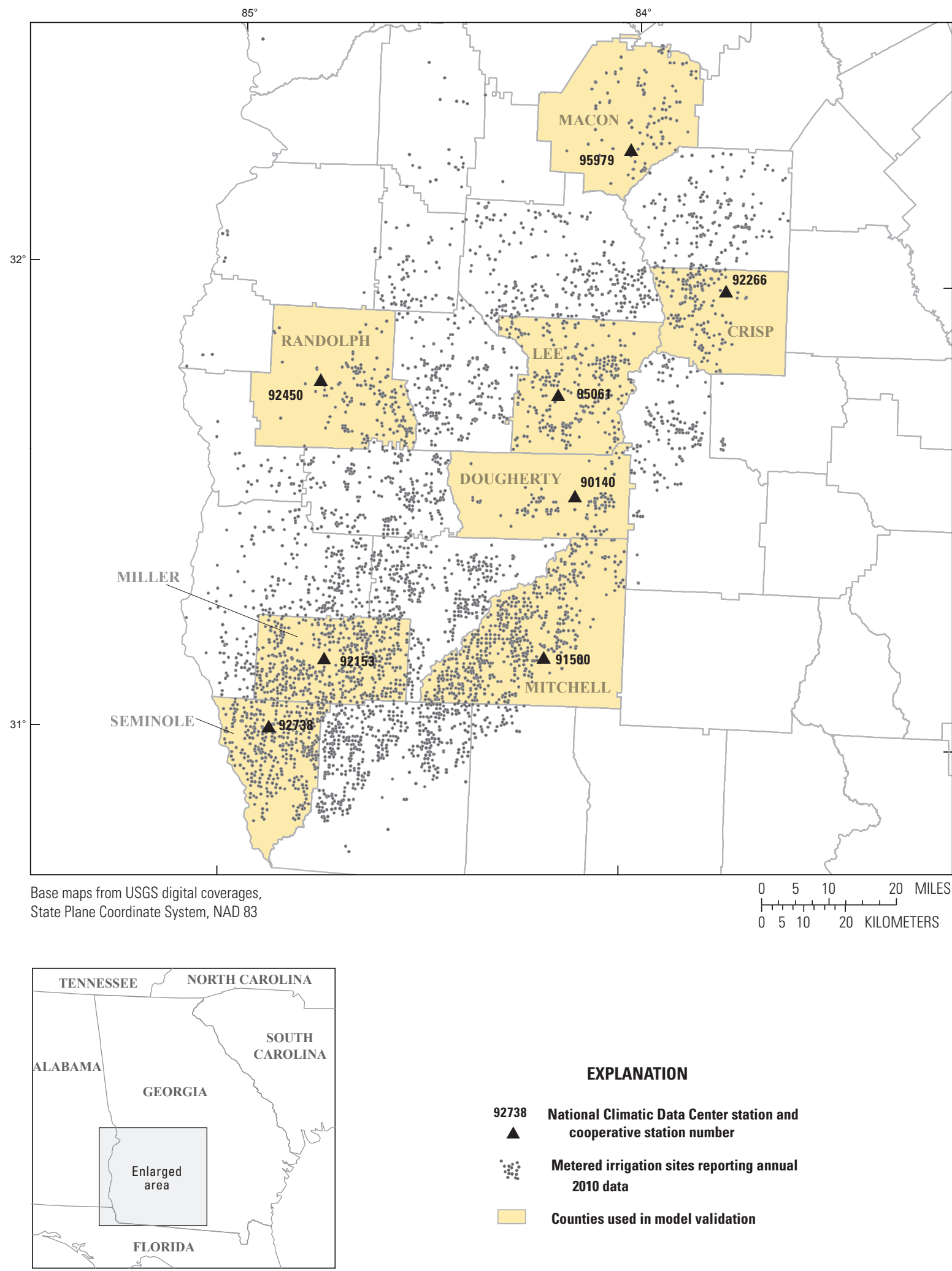

\section{EXPLANATION}

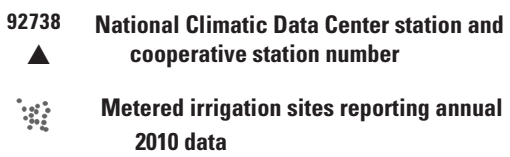

Counties used in model validation

Figure 7. Metered irrigation sites with 2010 annual data and National Climatic Data Center climate stations in southwestern Georgia. 

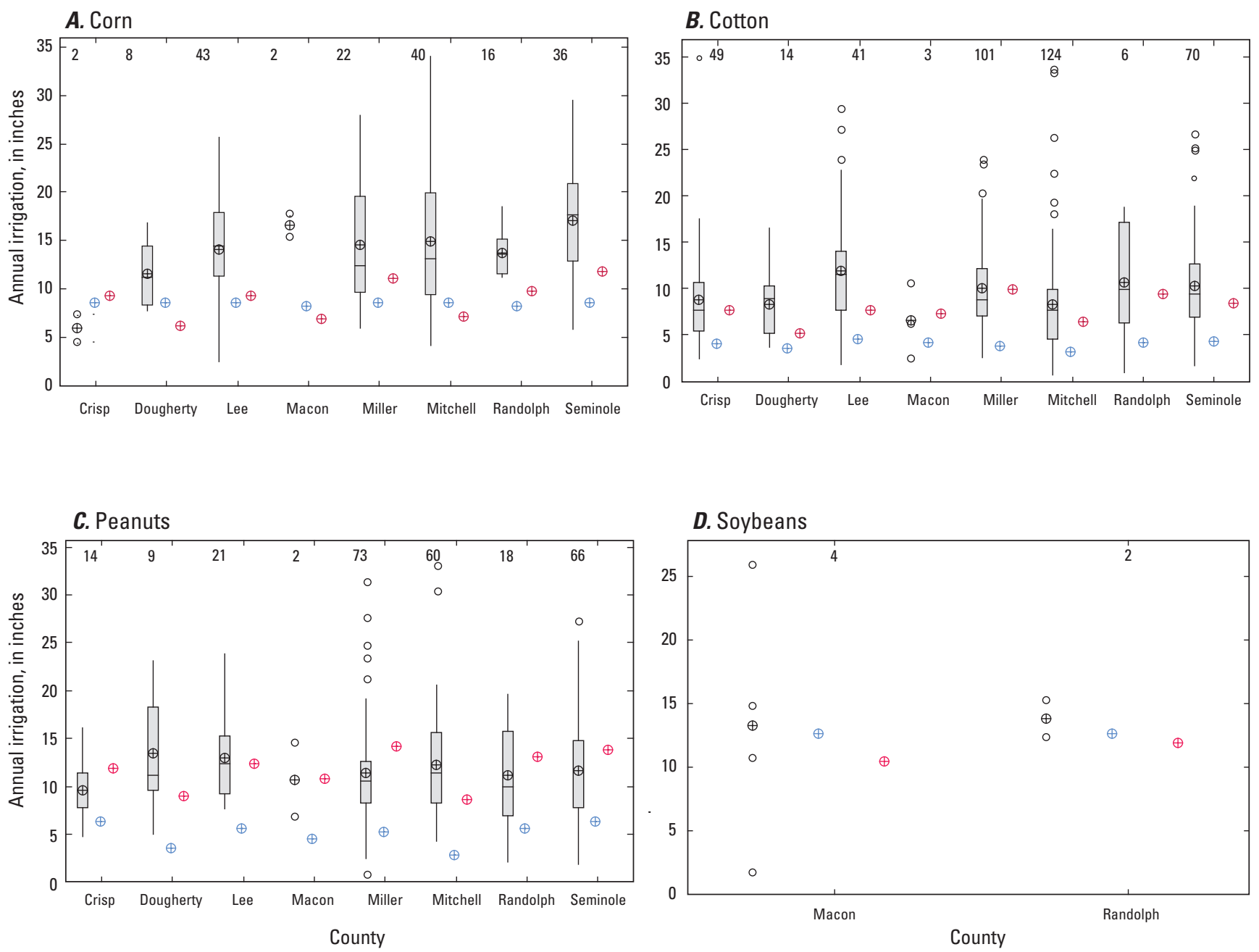

\section{EXPLANATION}

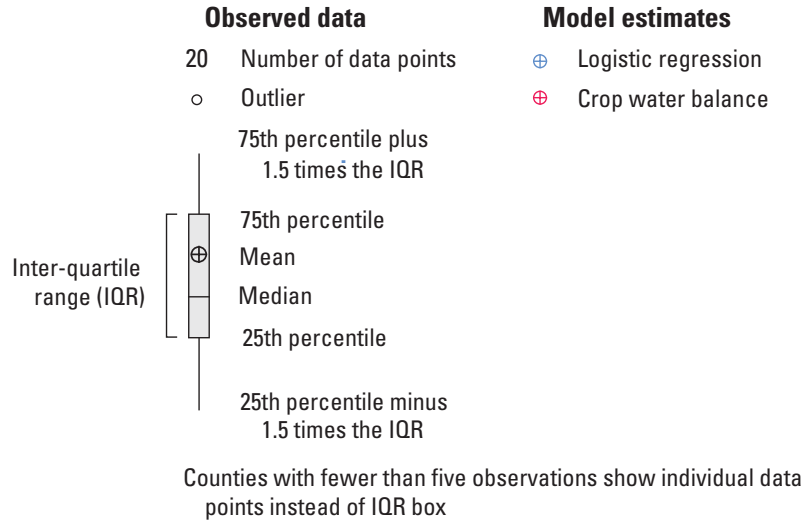

Figure 8. Reported data and model estimates of 2010 annual irrigation for $A$, corn; $B$, cotton; $C$, peanut; and $D$, soybean fields for selected counties in southwestern Georgia. 
Table 5. Reported data and model estimates of seasonal 2010 annual irrigation for corn, cotton, peanut, and soybean fields for selected counties in southwestern Georgia.

[RMSE, root mean squared error]

\begin{tabular}{|c|c|c|c|c|}
\hline \multirow[t]{2}{*}{ County } & \multirow{2}{*}{ Number of sites } & \multicolumn{3}{|c|}{$\begin{array}{l}\text { Average irrigation, } \\
\text { in inches per year }\end{array}$} \\
\hline & & Reported data & Crop-water-demand model & Logistic regression model \\
\hline \multicolumn{5}{|c|}{ Corn } \\
\hline Crisp & 2 & 5.8 & 9.3 & 8.6 \\
\hline Dougherty & 8 & 11.5 & 6.2 & 8.6 \\
\hline Lee & 43 & 14.1 & 9.2 & 8.6 \\
\hline Macon & 2 & 16.5 & 6.9 & 8.2 \\
\hline Miller & 22 & 14.6 & 11.1 & 8.7 \\
\hline Mitchell & 40 & 14.9 & 7.1 & 8.6 \\
\hline Randolph & 16 & 13.8 & 9.8 & 8.2 \\
\hline Seminole & 36 & 17.1 & 11.8 & 8.6 \\
\hline Mean & & 15.4 & 9.3 & 8.5 \\
\hline RMSE & & & 5.8 & 6.0 \\
\hline \multicolumn{5}{|c|}{ Cotton } \\
\hline Crisp & 49 & 8.7 & 7.5 & 3.9 \\
\hline Dougherty & 14 & 8.2 & 5.1 & 3.5 \\
\hline Lee & 41 & 11.3 & 7.6 & 4.5 \\
\hline Macon & 3 & 6.1 & 7.1 & 4.1 \\
\hline Miller & 101 & 9.9 & 9.9 & 3.7 \\
\hline Mitchell & 124 & 8.2 & 6.4 & 3.1 \\
\hline Randolph & 6 & 10.6 & 9.3 & 4.1 \\
\hline Seminole & 70 & 10.2 & 8.3 & 4.2 \\
\hline Mean & & 9.2 & 7.6 & 3.9 \\
\hline RMSE & & & 2.1 & 5.5 \\
\hline \multicolumn{5}{|c|}{ Peanut } \\
\hline Crisp & 14 & 9.5 & 11.8 & 6.3 \\
\hline Dougherty & 9 & 13.4 & 9.0 & 3.5 \\
\hline Lee & 21 & 12.9 & 12.4 & 5.6 \\
\hline Macon & 2 & 10.7 & 10.8 & 4.5 \\
\hline Miller & 73 & 11.4 & 14.1 & 5.2 \\
\hline Mitchell & 60 & 12.2 & 8.6 & 2.8 \\
\hline Randolph & 18 & 11.2 & 13.1 & 5.6 \\
\hline Seminole & 66 & 11.7 & 13.8 & 6.3 \\
\hline Mean & & 11.6 & 11.7 & 5.0 \\
\hline RMSE & & & 2.6 & 7.0 \\
\hline \multicolumn{5}{|c|}{ Soybean } \\
\hline Macon & 4 & 13.3 & 10.5 & 12.6 \\
\hline Randolph & 2 & 13.8 & 11.9 & 12.6 \\
\hline Mean & & 13.6 & 11.2 & 12.6 \\
\hline RMSE & & & 2.4 & 1.0 \\
\hline
\end{tabular}


The Virginia data are not metered and are considered less precise than metered data from Georgia and Rhode Island. For this reason and because of its temporal scale (monthly values), Virginia data were not used for model development. Potential data inaccuracies confound the evaluation of model performance, so additional screening was used to remove erroneous data to the extent possible. This included removing sites that reported applying 20 or more inches of water in a given month and sites that reported identical irrigation patterns in multiple years. After screening, 67 corn, 7 cotton, 30 soybean, and 11 turf sites with periods of record ranging from 1 to 7 years during 1999 to 2007 were available for analysis. No irrigation data were reported for peanut crops in Virginia.

Average annual irrigation rates in Virginia ranged from 2.0 to $8.3 \mathrm{in}$. for corn, 0.4 to $5.6 \mathrm{in}$. for cotton, and 1.6 to 6.9 in. for soybeans (table 6). In general, annual irrigation rates in Virginia for these crops were in the same range or lower than irrigation rates reported in Georgia. This is likely not only because of climatic differences but also because of the fact that the data from Georgia include some sites that were double cropped during the growing season, a practice that is not typical in Virginia.

Average turf irrigation in Virginia ranged from 5.2 to $14.2 \mathrm{in} / \mathrm{yr}$, which is roughly twice as much as average annual turf irrigation reported in Rhode Island. Monthly data indicate turf-grass irrigation in Virginia begins in March or April and continues through November, whereas in Rhode Island, turfgrass irrigation usually begins in April and continues through October. Higher irrigation rates in Virginia are likely because of the longer growing season and increased PET during the growing season.

The crop-water-demand models used in Virginia were modified slightly to reflect regional conditions. Soil water capacity was estimated from soil surveys and was set uniformly at 0.14 in. of water per inch of soil, and climate data were obtained from local NOAA climate stations. Crop coefficients (used to compute CPET) for the crop-water-demand model and the regression equations were kept the same for the row crops, except for corn, which is typically planted from mid-April to mid-May in Virginia and from mid-March to mid-April in Georgia (U.S. Department of Agriculture, National Agricultural Statistics Service, 1997). Corn crop coefficients were adjusted accordingly by offsetting the planting date by 30 days for Virginia. Soybean and cotton crops are planted at roughly the same time in Virginia as they are in Georgia, so no adjustment of the planting date was made to these crop coefficients. Weekly irrigation data were not available in Virginia to estimate specific irrigation application rates for use with the logistic regression equations; therefore, the same irrigation rates used for row crops in Georgia and turf in Rhode Island were used to estimate irrigation use in Virginia.

The RMSEs for crop-water-demand model estimates of statewide annual average irrigation compared to the reported volumes were 2.0, 2.9, 3.9, and 3.4 in. for corn, cotton, soybeans, and turf, respectively; the logistic regression RMSEs were 3.0, 1.8, 4.9, and 3.1 in., respectively, for the same crops (table 6). Annual irrigation rates can vary considerably across the state in a given year because of geographic and climatic differences. Therefore, annual irrigation predictions by both models were also compared for each county that reported data (fig. 9). The number of sites within a county was low; many counties have only one or two reported data points per year. The low sample size combined with the high degree of variability between sites and the large uncertainties associated with the reported data complicate the interpretation of the model results. Results are presented with the caveat that mean reported countywide irrigation for a particular year may be highly uncertain and affected by these factors.

Differences between estimated and reported mean annual irrigation were high with both models, but the crop-waterdemand models were better at capturing irrigation variability (fig. 9). Irrigation volume estimates by the crop-water-demand model for corn were mostly underestimated and estimates for soybeans were overestimated. In general, counties with high reported irrigation rates had high predicted irrigation rates and counties with reported low irrigation rates had low predicted values. Adjustments in model parameters, such as crop coefficients or application rates, that are based on local knowledge, could potentially reduce the bias and improve model results for these crops. Irrigation volume estimates by the logistic regression model for annual corn and soybean irrigation rates show little variability between sites and years, likely because precipitation is not included in the equation as an explanatory variable for these two crops. Both models performed similarly for turf-farm irrigation, overestimating irrigation in some years and underestimating in other years, but overall, the model estimates are well correlated with reported values. The logistic regression performed marginally better at predicting cotton irrigation than the crop-water-demand model, which overestimated irrigation. Additionally reported and predicted values were not correlated for either method, indicating an inability of either model to adequately describe cotton irrigation patterns in Virginia.

Mean monthly reported irrigation volumes were compared to predicted volumes from the crop-water-demand and logistic models (fig. 10) to determine the ability of the models to predict monthly patterns of irrigation water use. In general, the daily crop-water-demand models and the daily turf logistic models were better able to match the complex monthto-month water-use patterns of the reported data, particularly for turf. As mentioned previously, weekly logistic models have a limited number of outcomes that can be produced during a given month, regardless of the explanatory variables in the equation. This results in an oversimplified, peaked wateruse curve that does not always match reported water-use volumes. Additionally, because the corn and soybean logistic regression equations do not include antecedent precipitation as an explanatory variable, modeled irrigation has little variation from year to year despite differences in annual precipitation (fig. 10; table 6). 


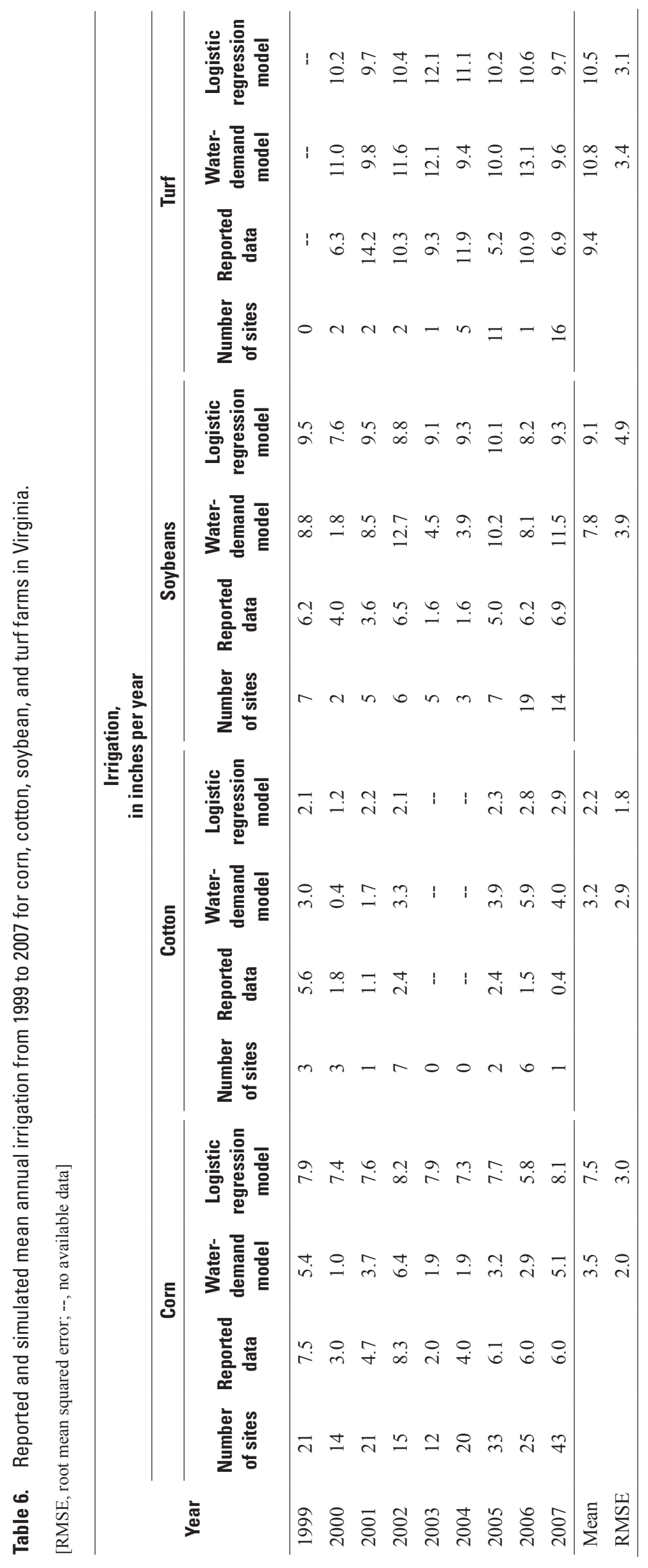



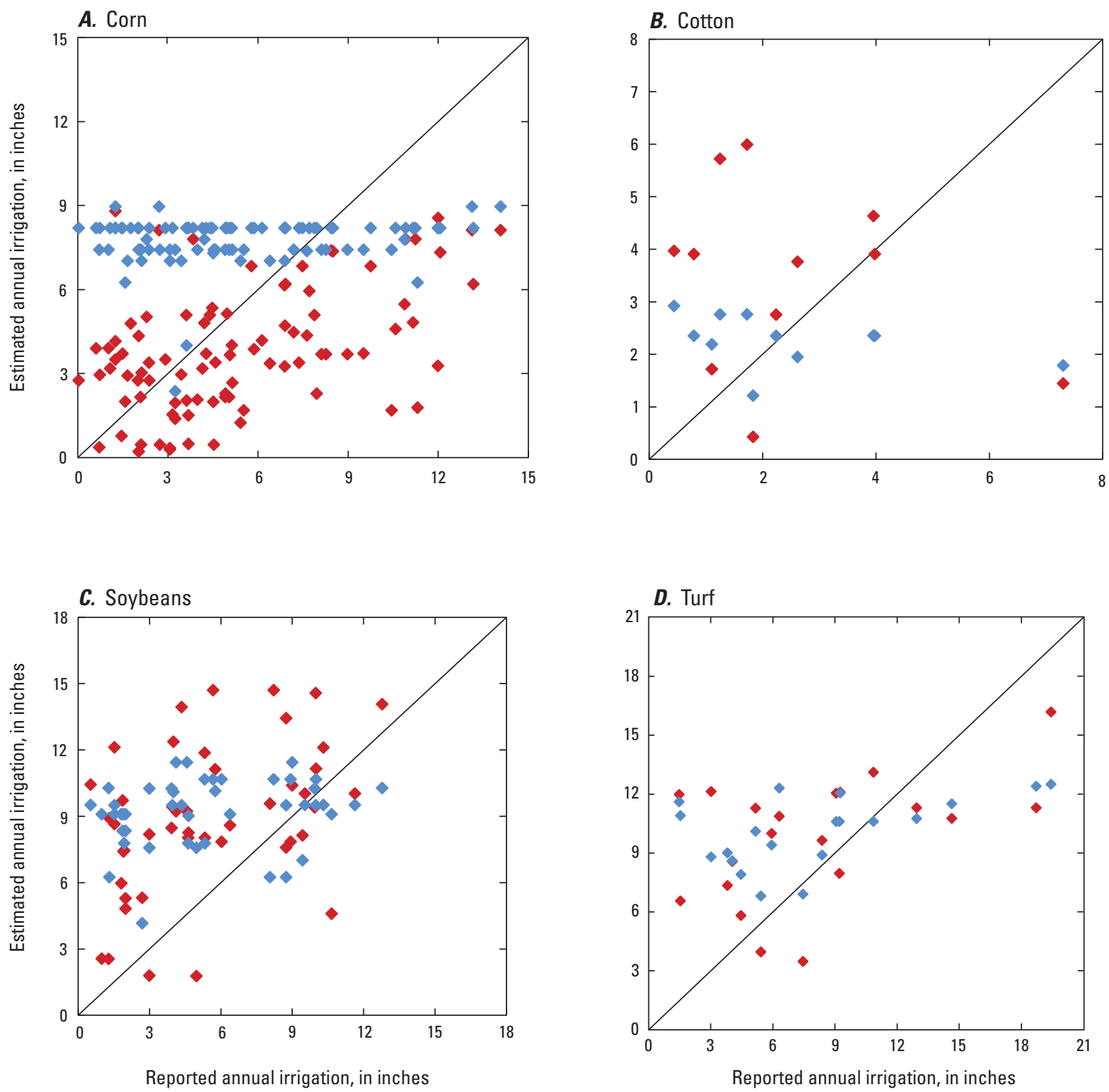

\section{EXPLANATION}

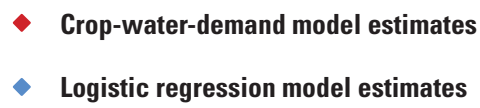

Figure 9. Reported data and model estimates of annual irrigation by county, for $A$, corn; $B$, cotton; $C$, soybeans; and D, turf crops in Virginia from 1999 to 2007. 

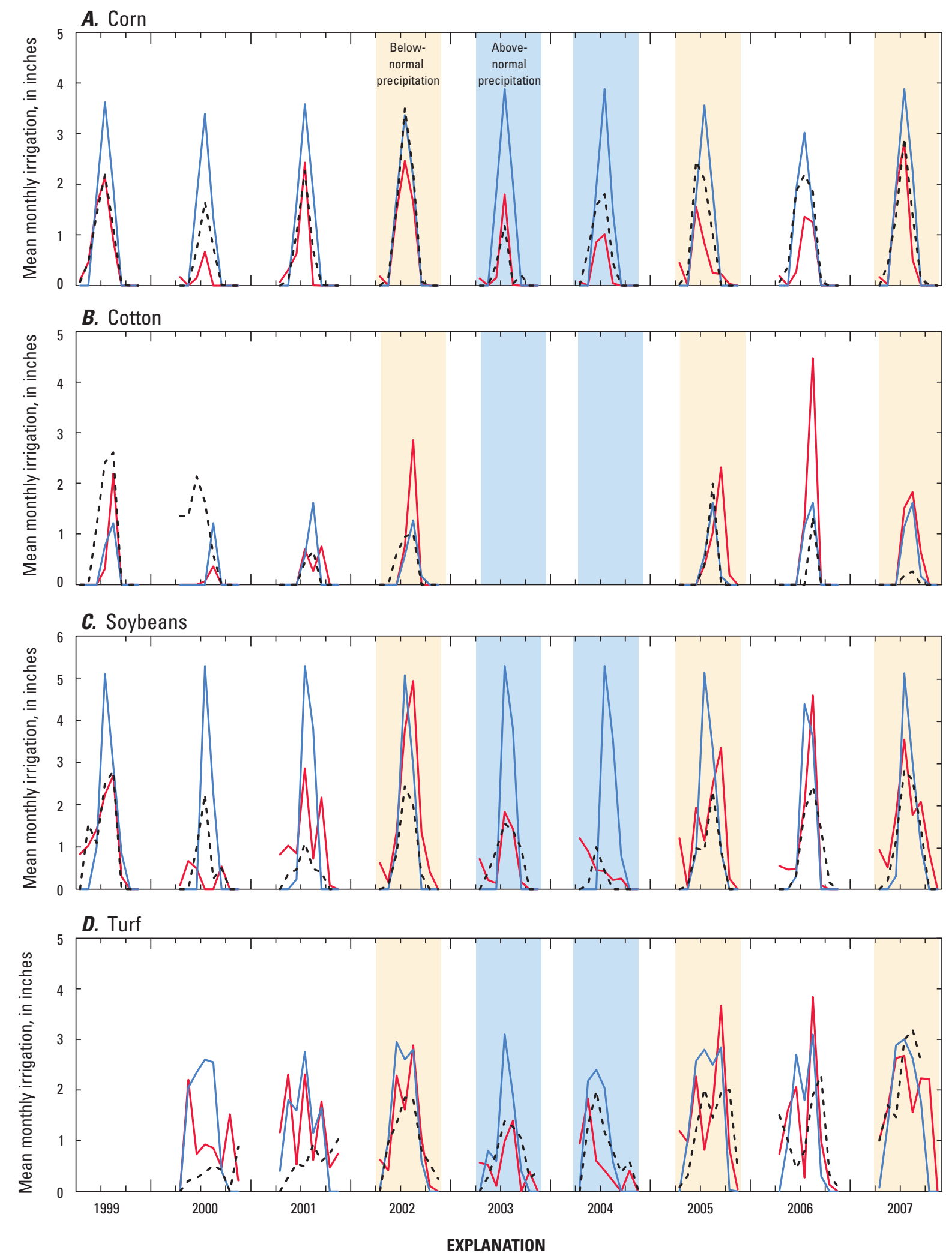

- . - Reported irrigation $\quad$ Crop-water-demand model $\quad$ Logistic regression model

Figure 10. Reported data and model estimates of mean monthly irrigation from 1999 to 2007 for $A, \operatorname{corn} ; B, \operatorname{cotton}$; $C$, soybean; and $D$, turf farms in Virginia. 


\section{Irrigation Model Transferability}

Logistic regression and crop-water-demand models developed for this study can be used to estimate irrigation in other eastern states in the study area. Crop-water-demand models are easily transferred to other regions and different crop types and can be customized to local agricultural conditions such as usual planting and harvesting dates, soil type, and crop coefficients. These models can be particularly useful at estimating irrigation water use in areas with little or no irrigation data because model parameters such as soil type, climate, and crop coefficients can be obtained from other sources. Logistic regression equations are based on actual water-use patterns and are inherently calibrated to the data used for model development. Equations may accurately predict irrigation within the geographic range where they were developed; however, they may not perform well in other areas where irrigation practices differ. Given sufficient quality data, it is possible to develop regional logistic regression equations to more accurately estimate irrigation water use in other eastern states.

Crop-water-demand and logistic regression models may not be appropriate to estimate irrigation water-use practices for some specialty crops grown in eastern states. Nursery and greenhouse horticultural crops are among the top three irrigated crops by acreage in many eastern states (table 7) and can require two to three times the amount of water used for field crops per unit area (Harrison, 2009b). The water needs of nursery plants depend largely on the container size, the spacing of plants, and the size of the inventory, which may change daily (Burger and others, 1987). These factors are unrelated to climate conditions making it unsuitable for a crop-waterdemand modeling approach. In addition, many greenhouse nurseries capture water that drains through potted plants and reuse the water.

Irrigation practices for berries and fruit trees also are unsuitable for estimation with crop-water-demand methods. Cranberries are an important crop in Massachusetts (table 7), but water use for this crop is primarily to flood fields during harvest or to prevent frost damage and is eventually returned to the lake or stream; thus, this is considered a nonconsumptive use and the irrigation-use methods in this study are not applicable. Water also is used to prevent frost or freeze damage to fruit trees and bushes such as apple trees and blueberry bushes. Because these water uses are unrelated to the crop water needs, crop-water-demand models are not appropriate for estimating this use.

\section{Study Limitations and Areas of Further Study}

Logistic regression and crop-water-demand models show promise for estimating regional irrigation water use at a monthly or annual time scale. Although models reproduced the general patterns of spatially aggregated, annual irrigation water use for independent datasets for corn, cotton, soybeans, peanuts, and turf, error rates for predicted irrigation at a specific site were high, and the models failed to capture the large site-to-site variability in the reported data. Inaccuracies in model predictions may arise from uncertainty in the data used to develop, calibrate, and validate the models and from uncertainty due to imprecise or unknown model parameter values such as crop coefficients or maximum allowable deficit values, particularly because these vary over the humid eastern United States. Factors not accounted for in the model, such as individual irrigation-system types and efficiencies, water availability, and economic factors, which influence decisions made by individual farmers to irrigate or not, also vary and affect the confidence of the model estimates.

The lack of quality irrigation data and ancillary information in the mid-Atlantic and New England States was the greatest limitation of the study; only through additional data collection and further study can the accuracy of irrigation water-use estimation be improved in these regions. Aside from the need for additional irrigation data, areas of further study that could improve the estimates of irrigation water use include better estimates of crop coefficients, application rates, and irrigated areas.

\section{Crop Coefficients}

This study used crop coefficients for the crop-waterdemand and the logistic regression models for agricultural crops in Georgia to specify the crop water requirement as a function of PET over the growth cycle of the crop. The coefficients are specified for a particular crop and are sensitive to many different factors such as soil type, humidity, average wind speed, crop variety, planting time, and the method of PET computation. Many of these factors are not reported with published estimates of crop coefficients. Jagtap and Jones (1989) found that crop coefficients required adjustments of \pm 30 percent in order to accurately estimate CPET under varying wind speeds, soil types, planting dates, PET estimation method, and humidity. Using crop coefficients in conditions different from those in which they were developed could cause inaccuracies in irrigation estimates.

Crop-water-demand models are highly sensitive to changes in crop coefficients. Crop coefficients are the most sensitive of the crop-water-demand model parameters, including root depth and soil water capacity (Satti and others, 2004). The sensitivities of crop coefficients for corn, cotton, peanut, and soybean crops in Georgia were tested by increasing their values by 10 and 20 percent and evaluating the effects on the logistic regression and crop-water-demand models. In the crop-water-demand model, increases of 10 and 20 percent in the crop coefficient increased total seasonal irrigation an average of 21 and 43 percent, respectively; total seasonal irrigation in the estimates from the logistic regression model increased comparably to the increases in the crop coefficient, by about 
Table 7. Primary irrigated crops in eastern states, by acreage, reported in the 2008 Farm and Ranch Irrigation Survey. Predominant fruit, vegetable, and berry crop types were determined using the 2007 Census of Agriculture.

[FRIS, Farm and Ranch Survey by the U.S. Department of Agriculture]

\begin{tabular}{|c|c|c|c|c|}
\hline State & Crop category from 2008 FRIS ${ }^{1}$ & $\begin{array}{l}\text { FRIS irrigated } \\
\text { acreage }^{2}\end{array}$ & $\begin{array}{l}\text { Percent of } \\
\text { total irrigated } \\
\text { acreage }\end{array}$ & Primary crops types in category ${ }^{3}$ \\
\hline \multirow[t]{4}{*}{ Connecticut } & All crops & 5,028 & & \\
\hline & Horticultural crops except sod & 2,756 & 55 & \\
\hline & Land in vegetables & 1,030 & 20 & Sweet corn, pumpkins, snap beans, tomatoes \\
\hline & Tobacco & 837 & 17 & \\
\hline \multirow{3}{*}{ Delaware } & Corn $^{4}$ & 50,131 & 43 & \\
\hline & Soybeans & 33,770 & 29 & \\
\hline & Vegetables & 16,401 & 14 & Lima beans, sweet corn, peas, cucumbers \\
\hline Georgia & All crops & $1,107,761$ & & \\
\hline \multirow[t]{5}{*}{ Maine } & All crops & 15,178 & & \\
\hline & Berries & 8,082 & 53 & Blueberries \\
\hline & Vegetables & 4,934 & 33 & Potatoes \\
\hline & Horticultural crops except sod & 759 & 5 & \\
\hline & Sod & 725 & 5 & \\
\hline \multirow[t]{4}{*}{ Maryland } & All crops & 105,014 & & \\
\hline & Corn $^{4}$ & 39,077 & 37 & \\
\hline & Soybeans & 26,119 & 25 & \\
\hline & Vegetables & 16,953 & 16 & $\begin{array}{l}\text { Sweet corn, snap beans, potatoes, green peas, } \\
\text { cucumbers }\end{array}$ \\
\hline \multirow{3}{*}{ New Hampshire } & Horticultural crops except sod & 806 & 53 & \\
\hline & Vegetables & 474 & 31 & Sweet corn, pumpkins \\
\hline & Berries & 119 & 8 & Blueberries \\
\hline \multirow[t]{4}{*}{ New Jersey } & All crops & 83,998 & & \\
\hline & Vegetables & 31,545 & 38 & $\begin{array}{l}\text { Sweet corn, cucumbers, tomatoes, peppers, } \\
\text { squash, snap beans, spinach, pumpkins, } \\
\text { potatoes }\end{array}$ \\
\hline & Horticultural crops except sod & 15,975 & 19 & \\
\hline & Berries & 11,391 & 14 & Blueberries \\
\hline \multirow[t]{4}{*}{ New York } & All crops & 29,189 & & \\
\hline & Vegetables & 11,314 & 39 & Sweet corn, snap beans, potatoes, green peas \\
\hline & $\begin{array}{l}\text { Land in orchards, vineyards, and } \\
\text { nut trees }\end{array}$ & 5,413 & 19 & Apples and grapes \\
\hline & Sod & 4,852 & 17 & \\
\hline
\end{tabular}


Table 7. Primary irrigated crops in eastern states, by acreage, reported in the 2008 Farm and Ranch Irrigation Survey. Predominant fruit, vegetable, and berry crop types were determined using the 2007 Census of Agriculture.-Continued

[FRIS, Farm and Ranch Survey by the U.S. Department of Agriculture]

\begin{tabular}{|c|c|c|c|c|}
\hline State & Crop category from 2008 FRIS ${ }^{1}$ & $\begin{array}{l}\text { FRIS irrigated } \\
\text { acreage }^{2}\end{array}$ & $\begin{array}{c}\text { Percent of } \\
\text { total irrigated } \\
\text { acreage }\end{array}$ & Primary crops types in category ${ }^{3}$ \\
\hline \multirow[t]{4}{*}{ North Carolina } & All crops & 182,026 & & \\
\hline & $\begin{array}{l}\text { All hay (dry hay, greenchop, and } \\
\text { silage) }\end{array}$ & 36,484 & 20 & \\
\hline & Corn $^{4}$ & 26,568 & 15 & \\
\hline & Cotton & 14,156 & 8 & \\
\hline \multirow[t]{3}{*}{ Pennsylvania } & All crops & 23,906 & & \\
\hline & Vegetables & 10,538 & 44 & Sweet corn, potatoes, snap beans, pumpkins \\
\hline & Horticultural crops except sod & 5,296 & 22 & \\
\hline \multirow{2}{*}{ Rhode Island } & Vegetables & 353 & 11 & \\
\hline & $\begin{array}{l}\text { Land in orchards, vineyards, and } \\
\text { nut trees }\end{array}$ & 158 & 5 & Apples and grapes \\
\hline \multirow[t]{5}{*}{ South Carolina } & All crops & 130,189 & & \\
\hline & Corn $^{4}$ & 39,930 & 31 & \\
\hline & Vegetables & 13,336 & 10 & $\begin{array}{l}\text { Watermelons, tomatoes, sweet corn, collards, } \\
\text { cucumbers, turnip greens, cantaloupes }\end{array}$ \\
\hline & Soybeans & 12,741 & 10 & \\
\hline & Sod & 12,538 & 10 & \\
\hline \multirow{3}{*}{ Virginia } & Corn $^{4}$ & 16,016 & 29 & \\
\hline & Vegetables & 11,170 & 20 & Snap beans, potatoes, tomatoes, sweet corn \\
\hline & Soybeans & 8,796 & 16 & \\
\hline \multirow[t]{5}{*}{ West Virginia } & All crops & 975 & & \\
\hline & Horticultural crops except sod & 383 & 39 & \\
\hline & Vegetables & 320 & 33 & Sweet corn, potatoes, pumpkins, tomatoes \\
\hline & $\begin{array}{l}\text { Land in orchards, vineyards, and } \\
\text { nut trees }\end{array}$ & 118 & 12 & Apples \\
\hline & Berries & 113 & 12 & Blueberries and blackberries \\
\hline
\end{tabular}

${ }^{1}$ Crop category and dominant crop types that comprise a combined total of about 70 percent or more of the total irrigated acreage in a state.

${ }^{2}$ Statewide irrigated acreage is the sum of the acreage of all irrigated crop categories in the 2008 FRIS. Acreage of fields that are double cropped are counted twice.

${ }^{3}$ Crop categories and types were determined from a combination of the Farm and Ranch Survey and Agricultural Census by the U.S. Department of Agriculture.

${ }^{4}$ Corn used for grain, seed, silage, or greenchop. 
9 and 16 percent, respectively. Thus, the crop-water-demand model is about twice as sensitive to the crop coefficient as the logistic regression model.

Crop coefficients vary from twofold to fivefold relative to the number of days after planting. Even when crop coefficients are well known, model uncertainty exists because planting dates can vary by a month or more in the same region, affecting the potential crop evapotranspiration. Crops planted later in the spring will generally require less water in June and July and more water later in the summer relative to crops planted in the early spring. Irrigation water use for cotton in Georgia estimated with the logistic regression and crop-water-demand models decreased by up to $2.5 \mathrm{in}$. when planting dates were delayed by 1 month. However, the effects of the planting date and the effects of the crop coefficient in general on estimated irrigation water use largely depend on precipitation during the growing season.

\section{Application Rate}

Irrigation water use estimated by the logistic regression equations is highly sensitive to the monthly application rate. Weekly irrigation depths computed in Georgia varied widely, ranging from 0.1 to more than $3.0 \mathrm{in}$. per week. Hence, the use of average monthly application values does not represent the highly variable rates in many cases. Percent errors in monthly application rates will cause a proportional percent error in the resulting total irrigation volume. Therefore, even though a logistic regression equation may be accurate at predicting the occurrence of irrigation on a given day or week, the resulting estimate of water volume used will be uncertain if the application rate is not well known.

The need for accurate monthly application rates is a potential limitation of the logistic regression method. Application rates vary not only by crop but also can be affected by soil type, climate conditions, water source, pumping capacity, and other factors. Estimates of total irrigation determined by logistic regression models could be improved by developing predictive models for application rates from factors that affect application rates or developing localized logistic regression models that inherently incorporate these factors.

Irrigation in the crop-water-demand model is determined by the computed water deficit needed to maintain the crop, and the application rate can vary depending on the maximum allowed deficit, which is determined by the userspecified MAD. In the present study, MAD was assumed to be 50 percent, but the value likely varies temporally and spatially. Uncertainty in MAD values has relatively minor effects on total irrigation predicted by the crop-water-demand model. Varying MAD by \pm 20 percent ( 40 and 60 percent of the maximum allowed deficit) in the crop-water-demand model resulted in relatively minor changes of 3 to 7 percent in total irrigation in corn, cotton, peanut, and soybean models. Specifying the maximum MAD value of 100 percent resulted in increases in total seasonal irrigation by 15 to 40 percent, which is equal to about 1 to $3 \mathrm{in} / \mathrm{yr}$, respectively.

\section{Irrigated Area}

In addition to accurately estimating when irrigation is used and at what rate, model estimates of total irrigation volume over a state or region also require accurate estimates of irrigated area by crop type. Published estimates of irrigated land vary widely. For example, in 2007, the farm and ranch survey (U.S. Department of Agriculture, National Agricultural Statistics Service, 2009a) reported 1.0 million acres of irrigated cropland in Georgia; however, the University of Georgia irrigation survey (Harrison, 2009b) reported 1.5 million acres of irrigated cropland for that year. Hence, statewide estimates of total annual irrigation water use can vary by hundreds of millions of gallons depending on which estimate of total irrigated area is used.

Remote sensing is frequently used to map irrigated acreage by comparing spatial patterns of vegetative indices such as the Normalized Difference Vegetation Index (NDVI) throughout the growing season combined with ancillary climate, topography, or other ground-based data (Masoner and others, 2003, Ozdogan and Gutman, 2008, Pervez and Brown, 2010, Qi and others, 2002). Although satellite imagery has been successful at distinguishing between irrigated and non-irrigated land in the arid or semiarid western United States, the contrast between spectral signatures from irrigated and non-irrigated lands is less discernible in the humid east (Ozdogan and others, 2010) but is an area of active research by the USGS Eastern Geographic Science Center (John Jones, U.S. Geological Survey, written commun., November 2011). The prospect of improved detection of irrigated lands together with the improved estimates of when irrigation is used can greatly improve estimates of irrigation water use in the eastern United States.

\section{Data Limitations}

The extent and quality of existing irrigation water-use data in the eastern United States is the biggest impediment to developing comprehensive accurate models for estimating irrigation water use in the region. Although efforts were made to collect all available irrigation data in the eastern United States, only statewide metered data from Georgia could be used with reasonable certainty. However, data from Georgia still required extensive screening because meter error and ancillary data required for model development, such as irrigated acreage and crop type, were incomplete. Attribute information was commonly determined by combining the irrigation data with other spatial information, which is another source of uncertainty. Irregularities also were found in the Georgia data, such as the fact that weekly total irrigation volumes did not always sum to the total annual reported irrigation volume for the site. These data limitations greatly 
reduced the size of the irrigation data set available for model development in Georgia, which correspondingly increases the uncertainty of the model, particularly the logistic regression model that is wholly dependent on a representative sample of the entire population. Hence, irrigation models developed from the Georgia data might not represent irrigation water use throughout the eastern United States.

Irrigation water-use data from Virginia were imprecise and highly uncertain because the data were largely estimated from pumping rates and the estimated time the pump was running. As a result, there were many inconsistencies in these data including irrigation volumes that were unreasonably high and irrigation rates that were identical from year to year or constant for each month. Although the data were screened to eliminate questionable data to the extent possible, screening methods were subjective, leaving the possibility that erroneous data are in the data set used in the analysis. The use of highly uncertain data complicates the interpretation of the validation results. Poor agreement between model predictions and the reported data could be a result of uncertainty in the model or uncertainty in the data. Conversely, good agreement between predicted and reported values could merely reflect similar biases in the model and reported data and not a true measure of the accuracy of model.

Quality irrigation data is needed in the eastern United States to develop tools to estimate irrigation water use over the region. These data need to be of known accuracy and need to be accompanied by other attribute information such as crop type, acreage irrigated, irrigation methods, and other characteristics, otherwise the data are of limited value for assessing and managing irrigation water use. Although widespread metering of irrigation in the eastern United States is unlikely in the near future, a stratified sample of metered irrigation water use in the region could help fill the gap in irrigation water-use data. The stratified sampling could be based on principal irrigation water use in each state, with as few as 6 to 10 sites to represent a unique crop type, irrigation method, and similar geomorphic and climatic area. Although the number of unique groups could potentially be large, the groups could be prioritized by crops with the highest irrigation water use and by the regions with the most stressed water resources. High-quality irrigation water-use data are essential for further development of the tools needed to help make informed watermanagement decisions for sustainable water resources.

\section{Summary and Conclusions}

Accurate accounting of irrigation water use is an important part of the U.S. Geological Survey National Water-Use Information Program and the WaterSMART initiative to help develop and maintain sustainable water resources in the Nation. Despite the importance of irrigation data for evaluating the water resources of the Nation, reliable estimates of irrigation water use are missing in most eastern states because of a lack of reporting requirements and estimation methods. Methods of estimating irrigation water use are further complicated by the high spatial and temporal variability of irrigation due to natural rainfall variability in the region.

Irrigation data from eastern states were compiled in order to develop models of irrigation water use in the region. The availability and quality of irrigation water-use data vary from state to state. About half the eastern states have no reporting requirement, and states that do require reporting of irrigation water use vary widely in the type of information that is required, the reporting time scale, and whether the data was metered, estimated from average pumping times, or determined by other means. With the exception of Georgia, States in New England and the mid-Atlantic regions do not presently (2012) require reported irrigation water-use data to be metered, and where irrigation data do exist, the data are typically based on estimated pumping rates and run times. These nonmetered data are subject to many uncertainties, and data screening revealed many inconsistencies. Quality issues associated with reported irrigation water use in the eastern United States, including some metered data in Georgia, precluded their use for model development. In addition, ancillary data such as crop type, irrigated acreage, irrigation method, or water source are commonly incomplete or missing.

Georgia required irrigation metering in 2003, resulting in statewide availability of quality controlled irrigation data. In addition to the annually reported metered data at over 4,000 sites, daily irrigation data from 55 sites in 2009 and weekly irrigation data from 76 sites in 2010 provided the basis for the irrigation models developed during this study. Irrigated acreage was reported with approximately half the daily and weekly data, which had to be supplemented with the National Cropland Data Layer and the Georgia irrigated lands data layer to determine crop type and irrigated acreage associated with the metered data. Sites for which crop type or acreage could not be determined were removed from the analysis.

Two methods of estimating irrigation water use were tested and compared. Logistic regression models and cropwater-demand models for corn, cotton, peanut, and soybean crops were developed from 2009 and 2010 metered data from Georgia. In addition, a previously developed daily logistic regression model for turf farms in Rhode Island was compared to a crop-water-demand model. Logistic regression models predict the use of irrigation based on antecedent climate and the temporal patterns of reported irrigation. The results of the regression model are combined with an applicable irrigation rate over the area irrigated to obtain an irrigation volume. Logistic regression equations accurately predicted when irrigation occurred 70 percent of the time for corn, 67 percent of the time for cotton, and 72 percent of the time for peanuts and soybeans. False negative and positive predictions were about equally balanced so the overall model performance for predicting irrigation over the 2009 and 2010 growing seasons was considered adequate. The use of a mean monthly application rate and a weekly time scale limited the ability of these models to adequately represent the high spatial variability seen in the 
reported data and were inconsistent at estimating irrigation on a site-to-site basis. However, models were able to estimate mean annual irrigation for each crop type within about \pm 2 in. of the mean reported irrigation water use.

Crop-water-demand models simulate the daily crop water deficit based on daily precipitation, evapotranspiration, and soil moisture. Unlike the logistic regression model, the cropwater-demand model does not require an applicable irrigation rate because this is determined by the water deficit computed by the model. Both methods, however, still require information on the crop type and area irrigated. The crop-waterdemand model did not perform as well as the logistic regression model when compared to the 2009 and 2010 Georgia irrigation data. Mean crop model irrigation estimates were within \pm 4 in. of the reported mean; however, the high variability between sites was better represented by the estimates from the crop-water-demand model than the estimates from the logistic regression model.

The logistic regression and crop-water-demand models were validated by using independent metered data reported annually at 846 sites in 8 counties in southwestern Georgia for 2010 and reported monthly at 132 sites in Virginia from 1999 to 2007. Model error was high for both modeling approaches; however, in general, the estimates from the crop-waterdemand model had lower RMSEs than the estimates from the logistic regression model for most crops. Crop-water-demand model estimates of monthly irrigation volumes for corn and soybeans matched reported patterns in Virginia better than the logistic model but were about the same as the logistic regression model for cotton and turf. Corn and soybean logistic regression equations do not include antecedent precipitation as an explanatory variable. Consequently, there was little variation from year to year in irrigation estimates despite differences in annual precipitation.

The logistic regression and crop-water-demand models developed for this study show promise for estimating regional irrigation water use at a monthly or annual time scale, although large uncertainties exist in model estimates. In general, the crop-water-demand model is more applicable to areas that lack adequate irrigation data, whereas the logistic regression equations work better when developed in areas that have reliable data available. Unfortunately, many areas in the eastern United States do not have the required level of irrigation data to develop logistic regression equations, underscoring an important limitation of this method.

Uncertainty in irrigation estimates from these methods exists because of imprecise or unknown model parameters such as crop coefficients or average application rates. In addition, factors such as irrigation-system efficiencies, water availability, and economic factors that influence irrigation decisions cause variability in irrigation data that are not accounted for in the models. Moreover, crop type and irrigated acreage must be known with more certainty in order to estimate total irrigation water use at a regional or statewide scale. Finally, comparisons between models and data could only reflect similar biases in both the model and the reported data and not the accuracy of model results. Only additional data collection and further study can improve the accuracy of irrigation water-use estimates in the humid eastern United States. Current statewide reporting programs could improve their data by requiring ancillary data such as the crop type, irrigated acreage, and method associated with reported water use and by encouraging the installation of water meters. Even though widespread water metering is infeasible in many states, the development of a small, stratified sample of quality metered irrigation sites across different regions of the east could help fill the data gap and provide sufficient information to develop a more accurate predictive models of irrigation water use. The stratified sampling could be based on principal irrigation water use in each state, with as few as 6 to 10 sites to represent a unique crop type, irrigation method, and similar geomorphic and climatic area.

\section{References Cited}

Al-Kaisi, M.M., and Bromer, I., 2009, Crop water use and growth stages: Colorado State University Extension, Fact Sheet No. 4.715, 3 p., accessed March 2011, at http://www.ext.colostate.edu/pubs/crops/04715.pdf.

Andales, A.A., Chavez, J.L., and Bauder, T.A., 2011, Irrigation scheduling - The water balance approach: Colorado State University Extension Fact Sheet 4.707, 6 p., accessed February 2011, at http://www.ext.colostate.edu/pubs/ crops/04707.html.

Aronson, L.J., Gold, A.J., Hull, R.J., and Cisar, J.L., 1987, Evapotranspiration of cool-season turfgrasses in the humid northeast: Agronomy Journal, v. 79, no. 5, p. 901-905.

Bent, G.C., Zarriello, P.J., Granato, G.E., Masterson, J.P., Walter, D.A., Waite, A.M., and Church, P.E., 2009, Simulated effects of water withdrawals and land-use changes on streamflows and groundwater levels in the Pawcatuck River basin, southwestern Rhode Island and southeastern Connecticut: U.S. Geological Survey Scientific Investigations Report 2009-5127, 254 p.

Burger, D.W., Hartin, Janet, Hodel, D.R., Lukaszewski, T.A., Tjosvold, S.A., and Wagner, S.A., 1987, Water use in California's ornamental nurseries: California Agriculture, v. 41, no. 9, 2 p.

Carrow, R.N., 1995, Drought resistance aspects of turfgrasses in the southeast-Evapotranspiration and crop coefficients: Crop Science, v. 35, no. 6, p. 1685-1690.

Fanning, J.L., Schwarz., G.E., and Lewis, W.C., 2001, A field and statistical modeling study to estimate irrigation water use at benchmark farms study sites in southwestern Georgia, 1995-96: U.S. Geological Survey Water-Resources Investigations Report 00-4292, 32 p. 
Food and Agriculture Organization of the United Nations, Water Development and Management Unit, 2011, Crop water information: Natural Resources and Environment Department, accessed March 2011, at http://www.fao.org/ $\mathrm{nr} /$ water/cropinfo.html.

Georgia General Assembly, 2003, 2003-2004 regular session-HB 579-Water resources; farm uses; watermeasuring device: Georgia General Assembly, accessed March 23, 2010, at http://www.legis.ga.gov/Legislation/ en-US/display/20032004/HB/579.

Guerra, L.C., Garcia, A.G., Hook, J.E., Harrison, K.A., Thomas, D.L., Stooksbury, D.E., and Hoogenboom, G., 2007, Irrigation water use estimates based on crop simulation models and kriging: Agricultural Water Management, v. 89, no. 3, p. 199-207. (Also available at http://dx.doi.org/10.1016/j.agwat.2007.01.010.)

Hamon, W.R., 1961, Estimation of potential evapotranspiration: Journal of the Hydraulics Division, Proceedings of the American Society of Civil Engineers, v. 87 , p. $107-120$.

Harrison, Kerry, 2009a, Irrigation scheduling methods: University of Georgia, College of Agricultural and Environmental Sciences, Cooperative Extension Bulletin 974, 8 p., accessed March 2011, at http://www.caes.uga.edu/ publications/pubDetail.cfm?pk_id=6116.

Harrison, Kerry, 2009b, 2008 irrigation survey: University of Georgia, College of Agricultural and Environmental Sciences, 2 p., accessed May 2012, at http://www.nespal. org/SIRP/agwateruse/facts/2009.0122.IrrSurvey08_misc pub.pdf.

Helsel, D.R., and Hirsch, R.M., 1992, Statistical methods in water resources: New York, Elsevier, Studies in Environmental Science 49, $522 \mathrm{p}$.

Hook, J.E., Hoogenboom, Gerrit, Paz, Joel, Risse, Mark, Bergstrom, John, and Mullen, Jeffrey, 2009, Assessing agricultural groundwater needs for the future-Identifying irrigated area and sources: Proceedings of the 2009 Georgia Water Resources Conference, accessed January 10, 2010, at http://www.nespal.org/SIRP/waterinfo/State/AWD/ AgWaterDemand_IrrArea.htm.

Hosmer, D.W., and Lemeshow, Stanley, 2000, Applied logistic regression ( $2 \mathrm{~d}$ ed.): New York, John Wiley and Sons, 375 p.

Jagtap, S.S., and Jones, J.W., 1989, Stability of crop coefficients under different climate and irrigation management practices: Irrigation Science, v. 10, no. 3, p. 231-244.
Kenny, J.F., Barber, N.L., Hutson, S.S., Linsey, K.S., Lovelace, J.K., and Maupin, M.A., 2009, Estimated use of water in the United States in 2005: U.S. Geological Survey Circular 1344, $52 \mathrm{p}$.

Lee, Dewey, ed., 2012, A guide to corn production in Georgia-2012: University of Georgia College of Agriculture and Environmental Sciences Cooperative Extension, $106 \mathrm{p}$.

Masoner, J.R., Mladinich, C.S., Konduris, A.M., and Smith, S.J., 2003, Comparison of irrigation water use estimates calculated from remotely sensed irrigated acres and state reported irrigated acres in the Lake Altus drainage basin, Oklahoma and Texas, 2000 growing season: U.S. Geological Survey Water-Resources Investigations Report 03-4155, 39 p.

Ozdogan, Mutlu, and Gutman, Garik, 2008, A new methodology to map irrigated areas using multi-temporal MODIS and ancillary data-An application example in the continental U.S.: Remote Sensing of Environment, v. 112, p. $3520-3537$.

Ozdogan, Mutlu, Yang, Yang, Allez, George, and Cervantes, Chelsea, 2010, Remote sensing of irrigated agricultureOpportunities and challenges: Remote Sensing, v. 2, no. 9, p. 2274-2304. (Also available at http://dx.doi.org/ 10.3390/ rs2092274.)

Peart, R.M., Curry, R.B., Rosenzweig, Cynthia, Jones, J.W., Boote, K.J., and Allen, L.H., Jr., 1995, Energy and irrigation in south eastern U.S. agriculture under climate change: Journal of Biogeography, v. 22, nos. 4/5, p. 635-642. (Also available at http://www.jstor.org/stable/2845964.)

Pervez, M.S., and Brown, J.F., 2010, Mapping irrigated lands at $250-\mathrm{m}$ scale by merging MODIS data and national agricultural statistics: Remote Sensing, v. 2, p. 2388-2412. (Also available at http://dx.doi.org/ 10.3390/rs2102388.)

Qi, S.L., Konduris, Alexandria, Litke, D.W., and Dupree, Jean, 2002, Classification of irrigated land using satellite imagery, the High Plains aquifer, nominal date 1992: U.S. Geological Survey Water-Resources Investigations Report 02-4236, $31 \mathrm{p}$.

SAS Institute, Inc., 1995, Logistic regression examples using the SAS system (1st ed.): Cary, N.C., SAS Institute, Inc., version $6,163 \mathrm{p}$.

Satti, S.R., Jacobs, J.M., and Irmak, Suat, 2004, Agricultural water management in a humid region-Sensitivity to climate, soil and crop parameters: Agricultural Water Management, v. 70, p. 51-65.

Solly, W.B., Pierce, R.R., and Perlman, H.A., 1998, Estimated use of water in the United States in 1995: U.S. Geological Survey Circular 1200, $71 \mathrm{p}$. 
Torak, L.J., and Painter, J.A., 2011, Summary of the Georgia agricultural water conservation and metering program and evaluation of methods used to collect and analyze irrigation data in the middle and lower Chattahoochee and Flint River basins, 2004-2010: U.S. Geological Survey Scientific Investigations Report 2011-5126, 25 p.

U.S. Bureau of Reclamation, 2012, AgriMet irrigation guide: U.S. Bureau of Reclamation, accessed March 2012 at http://www.usbr.gov/pn/agrimet/irrigation.html.

U.S. Department of Agriculture, National Agricultural Statistics Service, 1997, Usual planting and harvesting dates for U.S. field crops: Agricultural Handbook 628, 51 p., accessed March 2012, at http://www.nass.usda.gov/ Publications/Usual_Planting_and_Harvesting_Dates/ uph97.pdf.

U.S. Department of Agriculture, National Agricultural Statistics Service, 2009a, Farm and ranch irrigation survey (2008), v. 3 of Special studies: U.S. Department of Agriculture 2007 Census of Agriculture, pt. 1, 209 p.

U.S. Department of Agriculture, National Agricultural Statistics Service, 2009b, Cropland data layer metadata: U.S. Department of Agriculture, accessed January 10, 2011, at http://www.nass.usda.gov/research/Cropland/metadata/ meta.htm.

U.S. Department of Agriculture, National Agricultural Statistics Service, 2010, Cropland data layer metadata: U.S. Department of Agriculture, accessed January 10, 2011, at http://www.nass.usda.gov/research/Cropland/metadata/ meta.htm.

Westenbroek, S.M., Kelson, V.A., Dripps, W.R., Hunt, R.J., and Bradbury, K.R., 2010, SWB-A modified Thornthwaite-Mather soil-water-balance code for estimating groundwater recharge: U.S. Geological Survey Techniques and Methods, book 6, chap. A31, 60 p.

Zarriello, P.J., and Bent, G.C., 2004, A precipitation-runoff model for the analysis of the effects of water withdrawals and land-use change on streamflow in the UsquepaugQueen River basin, Rhode Island: U.S. Geological Survey Scientific Investigations Report 2004-5139, 75 p. 
Prepared by the Pembroke Publishing Service Center.

For more information concerning this report, contact:

Office Chief

U.S. Geological Survey

New England Water Science Center

Massachusetts-Rhode Island Office

10 Bearfoot Road

Northborough, MA 01532

dc_ma@usgs.gov

or visit our Web site at:

http://ma.water.usgs.gov 

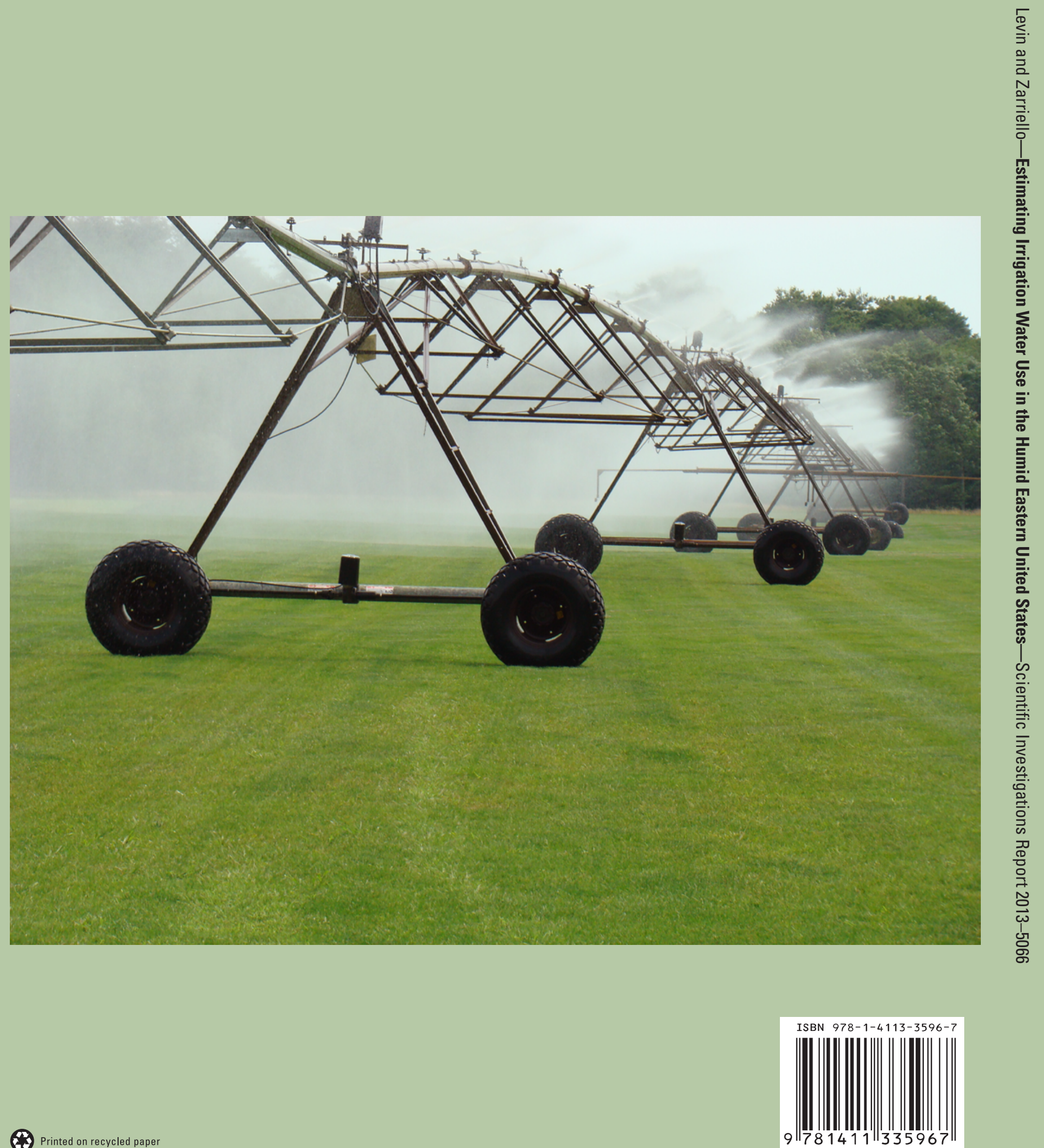